ISSN: 0213-2060

DOI: https://doi.org/10.14201/shhme2020382117152

\title{
PERTENECER Y DIFERENCIARSE. IGLESIAS «LOCALES» Y AGENCIA CAMPESINA EN EL NOROESTE DE LA PENÍNSULA IBÉRICA ${ }^{1}$
}

\author{
Belonging and Differentiation. Local churches and peasant agency in the northwest of \\ the Iberian Peninsula
}

Juan Antonio QUIRÓS CASTILLO

Depto. de Geografia, Prehistoria y Arqueologia. Campus de Álava. Universidad del País VascolEuskal Herriko Unibertsitatea. Cl Tomás y Valiente, s/n. E-01006VITORIA-GASTEIZ. C. e.: quiros.castillo@ehu.eus. Orcid: 0000-0002-4676-102X

Recibido: 2020-06-16

Revisado: 2020-09-07

Aceptado: 2020-10-26

RESUMEN: El objetivo de este trabajo es analizar las sociedades locales altomedievales del noroeste peninsular a partir de sus iglesias propias. La existencia de iglesias privadas fundadas por colectivos y líderes aldeanos de distinta entidad es bien conocida tanto a través de la documentación escrita como de la evidencia material. Estas construcciones han sido estudiadas desde el prisma de la emergencia de líderes aldeanos y élites locales que se proyectan hacia el exterior mediante la participación en redes clientelares vinculándose con los poderes de escala territorial. En este trabajo se pretende explorar las sociedades locales como espacios de participación, confrontación y negociación inter y extracomunitaria a través de la activación de políticas de pertenencia, diferenciación y exclusión articuladas a través de las iglesias locales. Para ello se confrontan dos regiones del noroeste, una de ellas caracterizada por la proximidad de la monarquía (Asturias) frente a otra distante respecto a los principales focos de poder en los siglos VIII-X (País Vasco). Las iglesias locales serán analizadas desde tres puntos de vista: las tecnologías constructivas, la relación entre las

1 Este trabajo ha sido realizado en el marco del Proyecto «Agencia campesina y complejidad sociopolítica en el noroeste de la Península Ibérica en época medieval» (Ministerio de Economía, Industria y Competitividad, AEI/FEDER UE HUM2016-76094-C4-2-R), del Grupo de Investigación en Patrimonio y Paisajes Culturales (Gobierno Vasco, IT936-16) y del Grupo de Estudios Rurales (Unidad Asociada UPV/ EHU-CSIC). Agradezco a Jordi Gibert i Recull, Josep María Vila, Robert Baró, Nerea Sarasola, Alex Ibáñez y Guillermo Tomás todas las referencias sobre Zarautz y las iglesias catalanas y aragonesas. Los comentarios y sugerencias de los evaluadores han contribuido a clarificar algunos puntos del trabajo. Una versión inicial del texto ha sido comentada y mejorada por Alfonso Vigil-Escalera y Carlos Tejerizo. No obstante, todas las inexactitudes son responsabilidad exclusiva del autor. 
iglesias y otros elementos constitutivos del paisaje social, y la construcción de las identidades en las sociedades locales en términos de larga duración.

Palabras clave: Asturias; País Vasco; Identidad relacional; Identidad individual; Territorialidad relacional.

ABSTRACT: This paper aims to analyse local early medieval societies in north-western Iberia through local proprietorial churches. The existence of private churches active at local scales is well known from the written sources and material evidence. Usually these buildings have been studied and viewed through the prism of the emergence of village leaders and local elites projecting their positions to the wider world by means of participation in client networks with regional territorial powers. This article attempts to explore local societies as arenas of confrontation and negotiation with the wider world through the creation of a politics of belonging, differentiation and exclusion, articulated through local churches. Two regions of the northwest are compared: one characterised by close proximity to the monarchy (Asturias) and the other by its distance from the principal focus of power between the $8^{\text {th }}$ and $10^{\text {th }}$ centuries (Basque Country). The local churches are studied from three perspectives: their technologies of construction, the relationship between the churches and other elements constituting the social landscape, and the construction of identities and local societies over the longer-term.

Keywords: Asturias; Basque Country; Relational identity; Individual identity; Relational territoriality.

SUMARIO: 0 Introducción. 1 Algunos problemas conceptuales y metodológicos. 2 Los registros materiales del País Vasco y Asturias. 2.1 País Vasco. 2.2 Asturias. 3 Iglesias «locales» y agencia campesina. 3.1 Tecnología y representación social. 3.2 Iglesias, cementerios y asentamientos. 3.3 Más allá del año mil. Las iglesias locales en el proceso de parroquialización. 4 Conclusiones. 5 Referencias bibliográficas.

\section{INTRODUCCIÓN}

Una de las principales innovaciones que tuvo lugar en los paisajes rurales de prácticamente toda Europa Occidental a partir del siglo viII fue la construcción de un gran número de iglesias y de monasterios propios (Eigenkirchen). Su número es abundante respecto a la Antigüedad Tardía, y a partir del período carolingio se encuentran en prácticamente cualquier lugar. Teniendo en cuenta su representatividad en las fuentes escritas, es comprensible que su estudio haya constituido uno de los ejes principales de la Historia Social de la Alta Edad Media. Además, estas construcciones han sido fundadas por todo el espectro social, desde los reyes, los poderosos, los grupos intermedios, hasta los estratos inferiores. En consecuencia, las iglesias privadas constituyen un escenario privilegiado 
para el análisis de múltiples aspectos políticos, sociales, económicos y religiosos de las sociedades altomedievales ${ }^{2}$.

En la Península Ibérica la mayor parte de los trabajos realizados sobre las iglesias propias altomedievales se han centrado principalmente en las iglesias promovidas por las élites supralocales debido, entre otros motivos, a su mayor visibilidad documental y material. La disponibilidad en algunos archivos de dosieres en los que se mencionan estas iglesias en donaciones, consagraciones, dotaciones y disputas ha permitido construir verdaderas genealogías de los señoríos territoriales. Además, la realización de numerosos estudios arqueológicos y arquitectónicos a lo largo de los últimos años como consecuencia de la progresiva afirmación de la Arqueología de la Arquitectura ha mostrado que el número de iglesias propias de carácter monumental es superior al que se sospechaba hace pocos decenios. Por todo ello, las iglesias propias fundadas por laicos o religiosos se han convertido en un campo de convergencia creciente entre los especialistas de los textos y de las disciplinas dedicadas a la arquitectura.

La densidad de prácticas sociopolíticas que se han tejido a partir de este tipo de fundaciones y su carácter polifuncional ha determinado que esta sea una de las principales líneas de investigación potenciadas por parte de los especialistas en la Alta Edad Media del norte peninsular. A través de estos trabajos se han analizado temáticas como la complejidad social, las formas de inserción de las élites en las sociedades locales, las formas de representación del estatus, las tecnologías constructivas y la organización de los talleres, los procesos de construcción de señoríos territoriales, el proceso de parroquialización y feudalización, la historia económica, etc. ${ }^{3}$

Han merecido, en cambio, una menor atención las iglesias propias realizadas por parte de las comunidades locales, esto es, el campesinado, los líderes aldeanos y otros grupos activos en marcos espaciales muy segmentados. Y a pesar de que la mayor parte de los estudios históricos regionales que han caracterizado la producción científica del

2 Blair, John. The Church in Anglo-Saxon society. Oxford: Oxford University Press, 2005; Wood, Susan. The proprietary church in the medieval West. Oxford: Oxford University Press, 2006; AdDison, David. "Property and 'publicness': bishops and lay-founded churches in post-Roman Hispania». Early Medieval Europe, 2020, vol. 282, pp. 175-196.

3 García Camino, Iñaki. Arqueología y poblamiento en Bizkaia, siglos VI-XII: la configuración de la sociedad feudal. Bilbao: Diputación Foral de Bizkaia, 2002; LARrea Conde, Juan José. "Construir iglesias, construir territorio: las dos fases altomedievales de San Román de Tobillas (Álava)». En Monasteria et territoria. Elites, edilicia y territorio en el Mediterráneo medieval (siglos V-XI). Oxford: Archaeopress, 2007, pp. 321-336; Caballero Zoreda, Luis y Utrero Agudo, María Angeles. "El ciclo constructivo de la Alta Edad Media hispánica. Siglos viII-X». Archeologia dell'architettura, 2013, vol. 18, pp. 127-146; Carvajal Castro, Álvaro. Bajo la máscara del "Regnum»: La monarquía asturleonesa en León (854-1037). Madrid: Consejo Superior de Investigaciones Científicas, 2017; GARCía DE CorTÁzAR, José Ángel. Sociedad y organización del espacio en la España medieval. Granada: Universidad de Granada, 2004; Pérez, Mariel. «Iglesias propias, élites rurales y poder eclesiástico en León (siglos XI-XIII)». En Comunidades en conflicto. Elites comunitarias y poder politico en la Península Ibérica (siglos IX a XVI). Buenos Aires: Universidad de Buenos Aires, 2018, pp. 41-67; SÁNCHEZ Pardo, José Carlos; Torre Llorca, María Jesús de la y Fernández Ferreiro, Marcos. «Élites, arquitectura y fundación de iglesias en Galicia entre los siglos IX y X». Reti Medievali, 2018, vol. 19, n. o 2, pp. 311-366; Carvajal Castro, Álvaro y Narbarte Hernández, Josu. "Royal power and proprietary churches in the eleventh-century Kingdom of Pamplona». Journal of Medieval Iberian Studies, 2019, vol. 11, pp. 115-134. 
norte de la Península Ibérica en los últimos decenios han mostrado su amplia difusión ${ }^{4}$, aún no han sido objeto de un tratamiento de conjunto.

Sin duda alguna el caso catalán es el mejor conocido, ya que en las más de 400 actas de consagración y dotación preservadas de los siglos IX y XII son frecuentes las referencias a fundaciones realizadas por comunidades y otros agentes locales 5 . Se trata, probablemente, de la mayor colección disponible en todo el Mediterráneo Occidental y tiene un valor indudable a la hora de iluminar la capacidad de agencia del campesinado y su participación en prácticas sociopolíticas poco documentadas en otros territorios. En palabras de P. Bonnassie, muchas de estas iglesias «locales» son «obra colectiva de los campesinos del lugar, que en los textos son llamados fundatores o edificatores, y la propia consagración es iniciativa exclusivamente suya ${ }^{6}$. No obstante, aún está pendiente por realizar un estudio conjunto de estos documentos y de los numerosos templos altomedievales indagados recientemente en las excavaciones preventivas o incluso preservados en alzado.

En el resto del noroeste peninsular la documentación conservada es menos elocuente, aunque tampoco faltan las referencias a iglesias propias fundadas por campesinos, líderes aldeanos y élites intermedias. En estos registros se observa que el control de bienes, derechos y privilegios que estaban asociados a estas iglesias constituía una pieza básica de la arquitectura de las sociedades locales. Sin embargo, la mayor parte de estos actos han sido realizados en el contexto en el que las iglesias salen de la órbita local para ser donadas a monasterios u otras instituciones externas a las comunidades ${ }^{7}$, por lo que resulta mucho más difícil evaluar qué razones determinaron el impulso de estas fundaciones o el impacto que pudo tener la construcción de estos nuevos centros de culto en las sociedades locales.

Pero ¿`cómo son estas iglesias?; ¿son similares a las construcciones eclesiásticas promovidas por las élites inferiores?; ¿por qué el campesinado lleva a cabo estas fundaciones?; ¿responde a una práctica de emulación o a otras pulsiones?; ¿qué tipo de prácticas sociales $\mathrm{y}$ actividades pastorales se llevan a cabo en estas iglesias?

El objetivo de este trabajo es doble. Por un lado, se pretende realizar un primer acercamiento a estas construcciones tomando en consideración, de forma prevalente, su dimensión material. Para ello se revisará el corpus de iglesias que los especialistas han identificado como fundaciones campesinas o de líderes locales. En segundo lugar, se analizarán las prácticas sociales que se desarrollan en y a partir de estos artefactos. Las

4 Entre los principales trabajos se pueden señalar los de DAvies, Wendy. Acts of giving: individual, community, and church in tenth-century Christian Spain. Oxford: Oxford University Press, 2007; MarTínez Sopena, Pascual. La tierra de Campos occidental: poblamiento, poder y comunidad del siglo X al XIII. Valladolid: Institución Cultural Simancas, 1985; ToMÁs FACI, Guillermo. Montañas, comunidades y cambio social en el Pirineo medieval: Ribagorza en los siglos X-XIV. Zaragoza: Prensas Universitarias de Zaragoza, 2016; MarTín VIso, Ińaki. Poblamiento y estructuras sociales en el norte de la Peninsula Ibérica (siglos VI-XIII). Salamanca: Universidad de Salamanca, 2000.

5 Ordeig I Mata, Ramon. Les Dotalies de les esglésies de Catalunya, segles IX-XII. Brcelona: Universitat de Barcelona, 1990.

6 Bonnassie, Pierre. Del esclavismo al feudalismo en Europa occidental. Barcelona: Crítica, 1992.

7 Por ejemplo, Escalona Monge, Julio. Sociedad y territorio en la Alta Edad Media castellana: la formación del Alfoz de Lara. Oxford, 2002; Davies, Wendy. Christian Spain and Portugal in the early Middle Ages: texts and societies. Abingdon: Routledge, 2020. 
comunidades locales serán consideradas como espacios de participación, confrontación y negociación inter y extracomunitaria que se articulan a través de la activación de políticas de pertenencia, diferenciación y exclusión. En definitiva, no se pretende tanto hacer una arqueología de las iglesias de las comunidades locales, cuanto una arqueología de las comunidades estructuradas en torno a iglesias locales.

Para llevar a cabo este análisis se han seleccionado dos regiones del noroeste que cuentan con una buena masa crítica de estudios arqueológicos, registros epigráficos y estudios dedicados a las iglesias propias: Asturias y el País Vasco. De esta manera será posible confrontar las prácticas sociales que se desarrollan en una región marcada por la proximidad de la monarquía frente a otra más distante respecto al poder central y que presenta notables diferencias comarcales. Ambos territorios cuentan, además, con sociedades locales notablemente jerarquizadas, aunque la escala de los sistemas políticos envolventes de los siglos viII y x sean diferentes en ambas regiones.

Este trabajo está dividido en tres partes. En primer lugar, se discuten algunos de los problemas metodológicos y conceptuales a los que se enfrenta el estudio de este tipo de registros. A continuación, se presentan algunos casos de estudio en las dos regiones seleccionadas. Por último, se analizan estas iglesias propias desde tres perspectivas: las tecnologías constructivas, la relación entre las iglesias y otros elementos constitutivos del paisaje social, y las formas de micropolítica que se desarrollan en las comunidades locales.

\section{Algunos PRoblemas Conceptuales y metodológicos}

El estudio de las iglesias propias de las comunidades locales es un camino plagado de dificultades. En primer lugar, de carácter conceptual. Tal y como se ha sostenido en trabajos previos ${ }^{8}$, el bajo nivel de teorización que suele manejar la arqueología altomedieval a la hora de caracterizar las sociedades campesinas condiciona la capacidad heurística del registro material. En este trabajo se asume que la noción misma de sociedad campesina implica necesariamente asimetría, subalternidad y relaciones jerárquicas de dependencia, por lo que conceptos como «espontaneidad», «libertad» o «independencia» campesina son totalmente inadecuados ${ }^{9}$. Pero, a su vez, no se puede negar la capacidad de agencia del campesinado, la coexistencia en la Alta Edad Media de una diversidad de fuentes de poder y de formas de interacción sociopolítica con las escalas supralocales y subregionales que desbordan la mera dependencia jerárquica. Con excepción de los esclavos, incluso los agricultores más humildes no han sido receptores pasivos ni han estado dominados de forma completa por las élites, de la misma manera que no se conocen sociedades campesinas plenamente autónomas ni desvinculadas de una compleja red de relaciones

8 Quirós Castillo, Juan Antonio. "An archaeology of 'small worlds': social inequality in early me-

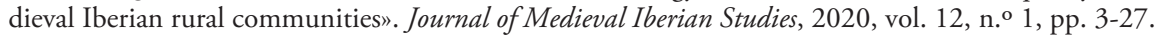

9 Sevilla Guzmán, Eduardo y Pérez Yruela, Manuel. «Para una definición sociológica del campesinado». Agricultura y Sociedad, 1976, vol. 1, pp. 15-39; Wolf, Eric R. Los campesinos. Barcelona: Labor, 1971. 
PERTENECER Y DIFERENCIARSE. IGLESIAS «LOCALES»

Y AGENCIA CAMPESINA EN EL NOROESTE DE LA PENÍNSULA IBÉRICA

JUAN ANTONIO QUIRÓS CASTILLO

de dependencia ${ }^{10}$. Las redes de cooperación, reciprocidad y solidaridad, y los mecanismos de negociación son tan importantes para comprender las dinámicas sociales del campesinado como lo son las relaciones jerárquicas basadas en el patronazgo, el dominio y el clientelismo ${ }^{11}$.

Ahora bien, estas prácticas de cooperación y solidaridad se desarrollan en el seno de comunidades locales, que aquí definiremos como una forma de agregación social conformada tanto por una serie de prácticas articuladas a partir de una interacción frecuente, así como por su dimensión espacial ${ }^{12}$. Es decir, es un marco social diferente y en cierto modo más amplio que el de la comunidad campesina tal y como se define en los siglos bajomedievales. En cambio, se reservará el concepto de sociedad local para referirse al espacio de interacción entre las comunidades locales y los grupos dominantes o sociedades envolventes. Constituye, por lo tanto, una escala de análisis supralocal y un objeto de estudio en sí mismo ${ }^{13}$.

Otro concepto de difícil delimitación es el de iglesia propia de una comunidad local o iglesia «local» ${ }^{14}$. El término de iglesia local ha sido empleado con anterioridad por varios especialistas, aunque no siempre ha sido definido de forma explícita ${ }^{15}$. Una de las principales dificultades que plantea acotar este concepto es que se trata de un fenómeno muy heterogéneo en términos territoriales y temporales. El nivel de localización de las prácticas sociales, religiosas y políticas en la Alta Edad Media es variable, hasta el punto de que la mayor parte de las iglesias altomedievales han de ser consideradas como locales. En este trabajo entendemos como iglesias «locales» aquellas fundaciones privadas, normalmente de carácter funerario, realizadas de forma colectiva o individual por sujetos que participan de redes sociales definidas por los horizontes políticos de una comunidad

10 Horden, Peregrine y Purcell, Nicholas. The corrupting sea: a study of Mediterranean history. Oxford: Wiley-Blackwell, 2000.

11 Pastor de Togneri, Reyna y Rodríguez López, Ana. «Reciprocidades, intercambio y jerarquía en las comunidades medievales». Hispania: Revista Española de Historia, 2000, vol. 204, pp. 63-101.

12 Sobre el concepto de comunidad ver Canuto, Marcello-Andrea y YAEger, Jason. Archaeology of communities: a new world perspective. London: Routledge, 2000.

13 Que se puede asociar a la noción de "small worlds», ver Davies, Wendy. Small Worlds: The Village Community in Early Medieval Brittany. Berkeley: University of California Press, 1988.

14 No es el único término utilizado. G. Tomás las denomina iglesuelas rurales u oratorios rústicos; Julia Barrow utiliza el concepto de «minor or local churches» y Susan Wood las define como «lower churches» o "Community churches». Este listado podría alargarse (ver Tomás FACI, Montañas, comunidades y cambio social en el Pirineo medieval; BARrow, Julia. The clergy in the medieval world: secular clerics, their families and careers in north-western Europe, c. 800-c. 1200. Cambridge: Cambridge University Press, 2015; Wood, The proprietary church in the medieval West).

15 Para John Blair la principal característica de las iglesias locales es «their lack of recorded endowments or of any independent public status before the critical changes of the eleventh century». Por su parte Charles Mériaux las define como aquellos templos que están «aux mains des laïcs pour reprendre una expression bien connue». Por su parte Sarah Hamilton recurre a una definición mucho más genérica al considerar las iglesias locales como aquellas fundaciones «in which some or all pastoral services are delivered to a lay congregation». La mayor parte de los especialistas que han trabajado en el norte peninsular no definen expresamente el término (ver Blair, The Church in Anglo-Saxon society; Hamilton, Sarah. Church and people in the medieval west, 900-1200. Abingdon, Oxon: Routledge, 2013; MérIAux, Charles. "La compétition autour des églises locales dans le monde franc». En Compétition et sacré au haut Moyen Âge: entre médiation et exclusion. Turnhout: Brepols, 2015, pp. 85-102. 
local. Con frecuencia, los fundadores suelen ser laicos, aunque también participan presbíteros o abades radicados en las comunidades locales. En palabras de J. Blair, las iglesias «locales» son una expresión de una comunidad ${ }^{16}$.

La tercera dificultad es de orden metodológico: ¿cómo identificar en el registro material al campesinado, los líderes aldeanos o las élites intermedias? ${ }^{17} \mathrm{La}$ subjetivación en términos sociales del registro material es siempre problemática, especialmente si se pretende caracterizar los grupos más humildes ${ }^{18}$. Además, en la Alta Edad Media los límites sociales en la esfera local, tanto por arriba como por abajo, son bastante difusos, por lo que distinguir los campesinos enriquecidos de la aristocracia inferior resulta particularmente complejo ${ }^{19}$. Es decir, la estructura de las sociedades locales reposa en una geometría social y escalar variable. Una consecuencia de ello es que los presbíteros poseedores de iglesias «locales» en el País Vasco actúan a escala meramente local, mientras que en Asturias aparecen en ocasiones con posesiones y activos en varias localidades ${ }^{20}$.

Otro reto importante es el que se refiere a las cronologías de estas construcciones. Sus características arquitectónicas y el escaso interés que ha despertado su estudio explican que hayan sido fechadas con horquillas pluriseculares. Normalmente estas iglesias se han datado, bien a partir de analogías formales genéricas, bien a partir de las sepulturas asociadas.

Pero quizás el principal problema es de orden epistemológico: ¿cómo se identifica en el registro material un fenómeno conocido a partir de los textos escritos? Si no supiésemos a través de los textos la existencia de iglesias de comunidades, ¿̇e podrían identificar autónomamente en el registro material?; ¿se caracterizarían en estos términos? Su estudio, ¿comporta una transposición de la evidencia escrita a la arquitectura, forzando las interpretaciones? Para evitar caer en esa trampa hay que ser cuidadosos. Salvo en casos muy concretos desconocemos la arquitectura de las iglesias atribuidas a las comunidades locales en las actas de consagración o de dotación, y viceversa. En consecuencia, será preciso interrogar los distintos registros de forma independiente.

El punto de partida que se asume aquí es que solamente cuando se cuenta con registros de calidad y de una cierta densidad es posible realizar cierto tipo de inferencias. En otras palabras, en ausencia de epígrafes o de documentos explícitos, solamente con la existencia de intervenciones arqueológicas extensivas que contextualicen las construcciones eclesiásticas en un marco espacial y social será posible identificar las funciones,

16 Blair, The Church in Anglo-Saxon society.

17 Por otro lado, tampoco resulta demasiado sencillo diferenciar en el registro textual el campesinado respecto a otros grupos sociales (Davies, Acts of giving.)

18 Hodder, Ian. Interpretación en arqueología: corrientes actuales. Barcelona: Crítica, 1988.

19 Álvarez Borge, Ignacio. "El proceso de transformación de las comunidades de aldea: una aproximación al estudio de la formación del feudalismo en Castilla (siglos x y xI)». Studia Historica. Historia Medieval, 1987, vol. 5, pp. 145-160.

${ }_{20}$ Quirós Castillo, Juan Antonio y Santos Salazar, Igor. «I villaggi medievali nell'Alto Ebro alla luce delle fonti scritte e dell'archeologia. L'emergere dei leader dei villaggi e l'articolazione dei poteri territoriali nel x secolo». En Paesaggi, comunità, villaggi medievali. Spoleto: Centro di Studi sull'Altomedioevo, 2012, pp. 257-282; García García, María Elida. «Pequeños propietarios en Asturias: (siglos X y XI)». Asturiensia Medievalia, 1986, vol. 5, pp. 33-53. 
los significados y los agentes activos en los centros eclesiásticos. Una segunda vía de estudio, paralela a la anterior, es la que proporciona la historia social de la arquitectura de base tecnológica, morfológica y funcional ${ }^{21}$. Combinando distintos enfoques es posible diferenciar, por ejemplo, iglesias «locales» gestadas de forma endógena en el seno de las comunidades respecto a las iglesias promovidas por élites externas, tal y como ocurre en los ejemplos alaveses de Zaballa o de Tobillas ${ }^{22}$. Pero no siempre se cuenta con registros de esta naturaleza o de estudios realizados desde estas perspectivas.

En este trabajo se ha partido de las atribuciones realizadas por los especialistas activos en las dos regiones de estudio y que cuentan, por lo tanto, con un cierto consenso entre la comunidad científica. A través de esta revisión se aspira a proponer itinerarios interpretativos que permitan conceptualizar en términos activos este grupo de arquitecturas más que describir sus características formales, tecnológicas o normativas.

Por último, un concepto clave que se utilizará a lo largo de este trabajo es el de identidad. Almudena Hernando ha desarrollado el concepto de identidad relacional contrapuesto al de identidad individual como un rasgo definitorio de grupos dotados de una reducida división de funciones y especialización del trabajo. Esta identidad no se define solamente a partir del tipo de relaciones sociales que se sostienen, sino ante la imposibilidad de concebirse fuera de un marco de relaciones y de prácticas de pertenencia que dan seguridad a cada una de las personas. Por contraposición, la identidad individual sería aquella a la que recurren sujetos que construyen relaciones asimétricas y de dominación dentro del grupo ${ }^{23}$. Una consecuencia que se deriva de esta asunción es que la cultura material no es un reflejo de adscripción a un grupo o la voluntad de diferenciarse, sino que sería un instrumento activo de construcción de una determinada realidad social.

\section{Los registros materiales del País Vasco y Asturias}

El recorrido histórico de Asturias y el País Vasco en los siglos viII y x presenta algunas diferencias importantes, pero también algunas analogías (fig. 1). Su carácter periférico en el período visigodo respecto a los poderes centrales determinó que a lo largo de los siglos VI y VII los poderes de carácter local adquiriesen un importante protagonismo. La materialidad de estos poderes, que han recurrido a lenguajes de distinción diferentes en ambas regiones, denota la diversidad de las escalas de los sistemas políticos y de los

21 Quirós Castillo, Juan Antonio y Fernández Mier, Margarita. «Para una historia social de la arquitectura monumental altomedieval asturiana». En Asturias entre visigodos y mozárabes. Madrid: Consejo Superior de Investigaciones Científicas, 2012, pp. 27-53.

22 Sobre Zaballa ver Quirós CAstillo, Juan Antonio. Arqueología del campesinado medieval: la Aldea de Zaballa. Bilbao: Universidad del País Vasco, 2012; sobre Tobillas ver Larrea Conde, "Construir iglesias, construir territorio».

23 Hernando, Almudena. La fantasía de la individualidad: sobre la construcción sociohistórica del sujeto moderno. Madrid: Katz Editores, 2012. La noción de identidad relacional ha sido formulada desde una perspectiva diferente en Ingold, Tim. Antropología: ¿por qué importa? Madrid: Alianza, 2020. 
discursos políticos ${ }^{24}$. La creación de nuevos sistemas políticos a partir del siglo viII vio la emergencia de un poder con tendencia centralizadora en Asturias, que se fue consolidando a lo largo del siglo Ix mediante una diversidad de formas de negociación, apropiación y ocupación, dando lugar al denominado Reino de Asturias ${ }^{25}$. La posición más periférica del actual País Vasco respecto al reino astur y el navarro durante estos siglos permitió un mayor grado de experimentación política y una mayor segmentación de los mecanismos de dominación. Hay un cierto consenso en admitir que, entre los siglos Ix y x, la mayor parte del País Vasco occidental fue integrada en la superestructura astur ${ }^{26}$. En ambas regiones se crearon en este período nuevos centros episcopales sobre los que pivotaron los resortes de los ambiciosos monarcas ovetenses. Resulta mucho más oscuro establecer cual ha sido el grado de influencia que han tenido en el País Vasco oriental el monarca y los obispos radicados en Pamplona en estos siglos.

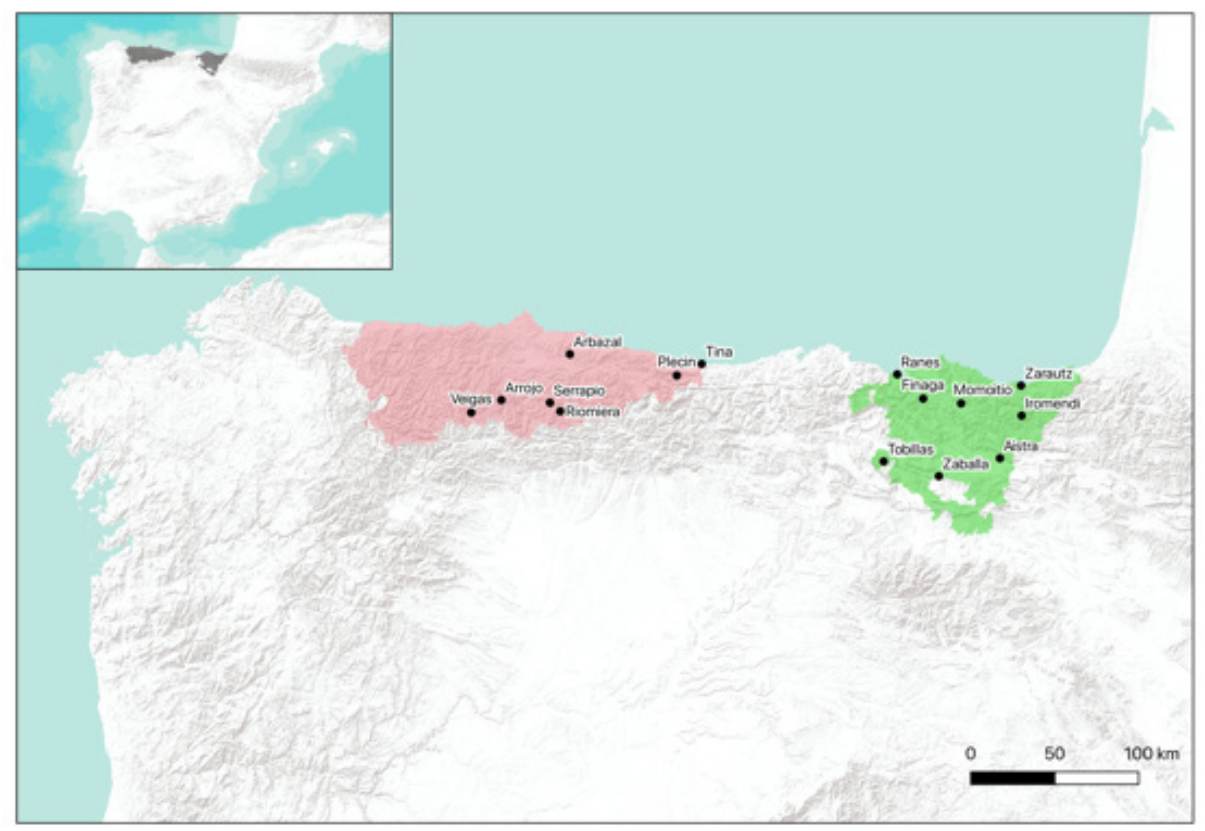

Figura 1. Mapa de las principales localidades mencionadas en el texto.

24 Esta diversidad se observa tanto en los registros funerarios, los centros de culto, así como en los lugares centrales.

25 Carvajal Castro, Bajo la máscara del "Regnum».

26 Sobre los mecanismos de construcción de la política del reino asturleonés, Martín Viso, Iñaki. «Las propiedades regias y la formación del Reino Asturleonés (850-950)». En Biens publics, biens du roi. Les bases économiques des pouvoirs royaux dans le haut Moyen Âge. Turnhout: Brepols, 2019, pp. 179-212; sobre el País Vasco y Castilla resulta iluminante Escalona Monge, Julio. «In the name of a distant king: representing royal authority in the county of Castile, c. 900-1038». Early Medieval Europe, 2016, vol. 24, pp. 74-102. 
Por lo que se refiere a las fuentes disponibles, ambas regiones muestran algunas similitudes y diferencias. Por un lado, conservan un reducido corpus documental en comparación con otros sectores del norte de la Península Ibérica. Además, salvo por algunas fuentes cronísticas, la totalidad de los textos proceden de archivos eclesiásticos, cuyas prácticas de transmisión documental han condicionado notablemente la entidad y la calidad de las informaciones disponibles ${ }^{27}$. Además, no todas las comarcas están igualmente representadas, de manera que Guipúzcoa no se menciona en los textos antes del ańo $1025^{28}$. Un rasgo común en ambas regiones es que, salvo en el caso de Álava, casi no hay referencias explícitas a iglesias propias fundadas por comunidades locales.

Otra fuente de interés es la colección de epígrafes altomedievales que han llegado hasta nuestros días. Las excelentes ediciones realizadas hace unos años muestran que la fundación de iglesias generó distintas formas de conmemoración en los dos territorios. El número de epígrafes de consagración y de fundación conservados en Asturias es muy superior respecto a los hallados en el País Vasco. En cambio, los epígrafes funerarios son más abundantes en el País Vasco que en Asturias. Dentro del País Vasco hay una mayor concentración de epígrafes en Vizcaya respecto a Álava, mientras que está pendiente por realizar el inventario de Guipúzcoa ${ }^{29}$. Estas diferencias no se corresponden con la difusión de la cultura escrita, sino con la existencia de diferentes mecanismos de construcción de la memoria social ${ }^{30}$.

Por último, en ambos territorios se han realizado destacados trabajos de carácter arquitectónico y arqueológico sobre el patrimonio eclesiástico. Los abundantes estudios dedicados a la denominada "arquitectura prerrománica asturiana» han abordado desde una diversidad de enfoques las formas, las funciones, las tecnologías y los significados de estas construcciones ${ }^{31}$. La trayectoria de estudios en el País Vasco es de signo distinto, debido a la modestia de las construcciones conservadas en alzado. No obstante, las excavaciones, prospecciones y lecturas de alzados realizadas en los últimos ańos permiten contar con un volumen significativo y representativo de arquitecturas eclesiásticas

27 Para el caso de Asturias ver Sanz Fuentes, María Josefa y Calleja Puerta, Miguel. Litteris confirmentur: lo escrito en Asturias en la Edad Media. Oviedo: Cajastur, 2005. Para el País Vasco ver GARCía DE Cortázar, José Ángel; Arízaga Bolumburu, Beatriz; Martínez Ochoa, Rosa M. et al. Introducción a la Historia Medieval de Álava, Guipúzcoa y Vizcaya en sus textos. San Sebastián: Txertoa, 1979.

28 Carvajal Castro, y Narbarte Hernández, «Royal power and proprietary churches».

29 Azkarate-Garai Olaun, Agustín y García Camino, Iñaki. Estelas e inscripciones medievales en el País Vasco occidental (ss. VI-XI). Bilbao: Universidad del País Vasco, 1996; Diego Santos, Francisco. Inscripciones medievales de Asturias. Oviedo: Gobierno del Principado de Asturias, 1995.

30 De hecho, resulta llamativo el contraste existente en la cultura epigráfica del País Vasco y del contiguo territorio burgalés. Ver Castresana López, Álvaro. Corpus Inscriptionum Christianarum et Mediaevalium Provinciae Burgensis: (ss. IV-XIII). Oxford: Archaeopress, 2015.

31 La bibliografía es muy abundante. Entre los principales trabajos se pueden citar los de GARCÍA DE Castro Valdés, César. Arqueología cristiana de la Alta Edad Media en Asturias. Oviedo: RIDEA, 1995; ArIAS PÁramo, Lorenzo. Enciclopedia del prerrománico en Asturias. Aguilar de Campoo: Fundación Santa María la Real, 2007; Utrero Agudo, María Ángeles. Iglesias altomedievales en Asturias: Arqueología y Arquitectura. Madrid: Consejo Superior de Investigaciones Científicas, 2016. 
altomedievales ${ }^{32}$. Un estudio comparativo de las iglesias «locales» de ambas regiones permitirá comprender las estrategias de legitimación y las prácticas sociales llevadas a cabo por las élites y las comunidades locales.

\subsection{País Vasco}

Empezaremos nuestro recorrido por Guipúzcoa, en donde se han hallado algunas iglesias «locales» de particular interés. La mayor parte de los autores han considerado que Guipúzcoa es el territorio menos jerarquizado y complejo en términos sociales de todo el País Vasco, hasta el punto de que constituiría un paradigma del predominio del modo de producción campesino ${ }^{33}$. Sin embargo, los estudios recientes realizados sobre los patrones de poblamiento o las prácticas agrarias están poniendo en cuestión esta caracterización, ya que muestran notables similitudes con las tendencias similares a las observadas en los espacios próximos ${ }^{34}$.

San Pedro de Iromendi (Bidania-Goiatz), es uno de los ejemplos de iglesias «locales» guipuzcoanas más interesantes conocidos hasta la fecha (fig. 2). Las excavaciones realizadas en los últimos años por Iosu Etxezarraga en el despoblado medieval situado en el cerro de Sanpedroburu ha permitido reconocer una iglesia delimitada por postes verticales de madera. Se trata de un edificio de 3,7x3 m definido por una decena de agujeros realizado en el siglo viII, quizás en la primera mitad. La existencia de varios enterramientos alineados y adyacentes a este edificio han permitido identificar su funcionalidad. Hacia el 1100 el edificio fue reconstruido y ampliado mediante la realización de un ábside rectangular de piedra, aunque la nave siguió siendo de madera. Sus dimensiones siguieron siendo muy modestas, ya que se han estimado en 3,5x4,5 m. Además, se ha documentado una segunda serie de enterramientos asociados a este edificio. Aunque el templo se mantuvo en uso durante un largo período, el abandono del cementerio a lo largo del siglo XIII permite pensar que fue en este momento cuando se produjo el despoblamiento del lugar. La capilla fue reformada en otras dos ocasiones, hacia el $1300 \mathrm{y}$ hacia el 1520, hasta que fue derruida en la segunda mitad del siglo xIx $^{35}$.

Esta es, hasta la fecha, la única iglesia altomedieval conocida en el País Vasco realizada únicamente con materiales lignarios. No obstante, varios especialistas han propuesto

32 Los principales trabajos son los de García Camino, Arqueología y poblamiento en Bizkaia; ETXEZARRaga Ortuondo, Iosu. El laicado y sus instituciones en la configuración religiosa de Gipuzkoa en la Edad Media. Tesis Doctoral. Universidad del País Vasco, 2017; Sarasola, Nerea y Moraza, Alfredo. Arkeologia 0.5 - Arqueologia Medieval en Gipuzkoa. San Sebastián: Diputación Foral de Gipuzkoa, 2012; SÁnchez ZuFIAURRE, Leandro. Técnicas constructivas medievales: Nuevos documentos arqueológicos para el estudio de la Alta Edad Media en Álava. Vitoria-Gasteiz: Gobierno Vasco, 2007.

33 Entre otros, Wicкham, Chris. "Conclusiones». En Vasconia en la Alta Edad Media, 450-1000: poderes y comunidades rurales en el norte peninsular. Bilbao: Universidad del País Vasco, 2011, pp. 87-90.

34 Narbarte Hernández, Josu; Iriarte, Eneko; Rad, Carlos, et al. «On the origin of rural landscapes: Looking for physico-chemical fingerprints of historical agricultural practice in the Atlantic Basque Country (N Spain)». Science of the Total Environment, 2019, vol. 681, pp. 66-81.

35 Etxezarraga Ortuondo, El laicado y sus instituciones; Etxezarraga Ortuondo, Iosu. «San Pedro de Iromendi: VI Campaña». Arkeoikuska: Investigación Arqueológica, 2017, pp. 358-363. 
PERTENECER Y DIFERENCIARSE. IGLESIAS «LOCALES»

Y AGENCIA CAMPESINA EN EL NOROESTE DE LA PENÍNSULA IBÉRICA

JUAN ANTONIO QUIRÓS CASTILLO

que este tipo de técnicas habría sido empleado de forma común en la realizacion de otros edificios religiosos promovidos por las comunidades locales ${ }^{36}$. Serían construcciones modestas que han sido realizadas sobre humildes zócalos de piedra sobre los que se levantarían alzados en mampostería o técnicas mixtas, como podría ser el caso de San Pedro de Elkano, San Salvador de Getaria o la primera fase de Santa María de Zarautz ${ }^{37}$.

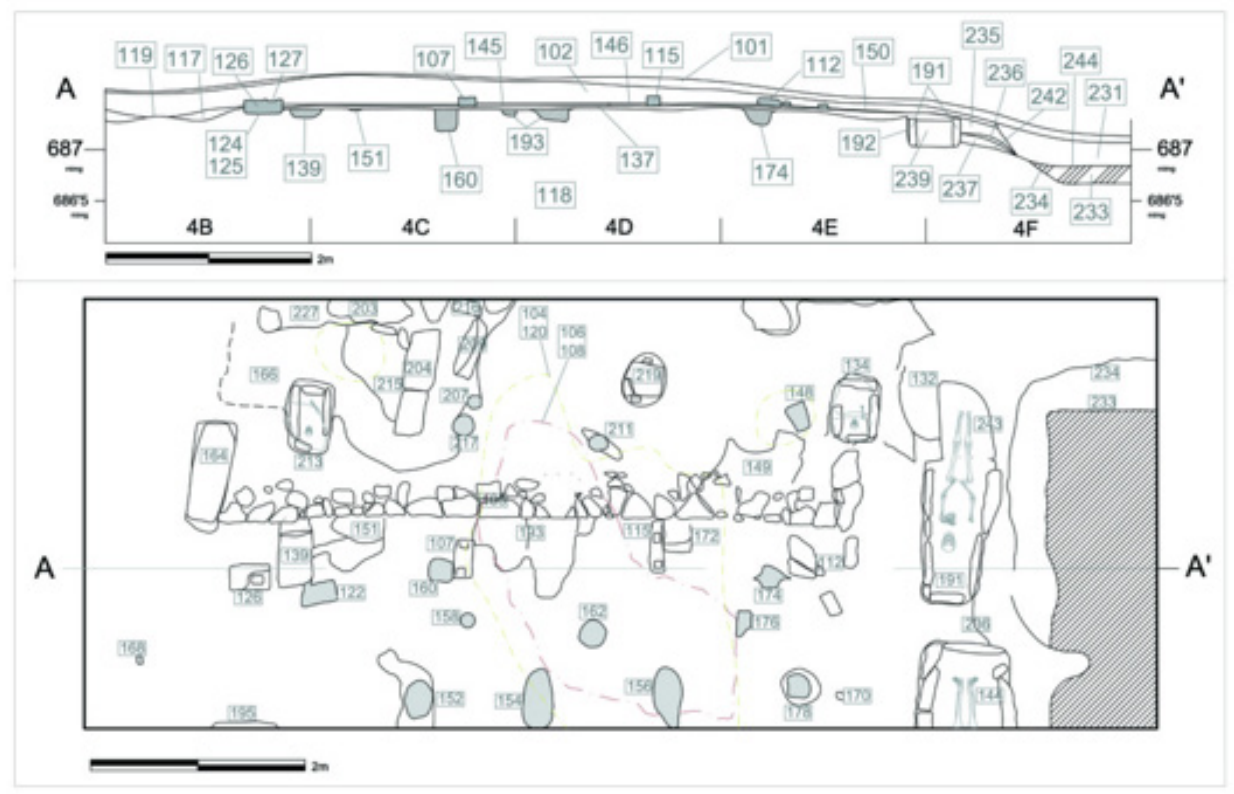

Figura 2. Planta de San Pedro de Iromendi, según Iosu Etxezarraga.

Las excavaciones realizadas en el interior de la iglesia parroquial de la villa guipuzcoana de Zarautz han permitido reconocer una compleja secuencia ocupacional que arranca en la Edad del Hierro y se prolonga, con algunas interrupciones, hasta nuestros días (Ibáńez, 2009). En el ábside del templo bajomedieval se han hallado los restos de un edificio de época romana, al que se adosa parcialmente un zócalo de mampostería trabada con argamasa que define una iglesia rectangular de $6,5 \mathrm{~m}$ de anchura y una longitud de, al menos, $7 \mathrm{~m}$ (fig. 3). Esta primera iglesia, que ha sido fechada en el siglo Ix, está asociada a una necrópolis que se remonta al siglo vIII. Al igual que otras iglesias altomedievales próximas se piensa que su alzado habría sido realizado en mampostería, aunque teniendo en cuenta las características de la cimentación quizás pudo haber sido construida con una

36 Otras iglesias que han sido atribuidas a fundaciones de comunidades campesinas son las de San Miguel de Irura y Santa Lucía de Gerrika (GARcía CAMıno, Ińaki. “Zarautz antes que Zarautz'. La primitiva aldea en el contexto de la historia altomedieval de los territorios del litoral vasco». Munibe. Suplemento, 2009, vol. 27, pp. 376-399).

37 Sarasola y Moraza, Arkeologia 0.5 - Arqueologia Medieval en Gipuzkoa. 
técnica mixta ${ }^{38}$. Poco tiempo después se construyó un segundo templo reemplazando al anterior que ha sido fechado en los siglos X-XI. Se trata de un edificio algo mayor (al menos $9 \mathrm{~m}$ de longitud) y presenta una división entre un presbiterio realzado y una nave dotada de un pavimento de tierra compacta. En esta ocasión la cimentación preservada permite pensar que los alzados fueron levantados completamente en mampostería, salvo la cubierta lignaria. El cementerio de esta iglesia está conformado por tumbas de lajas fechadas entre los siglos X-XIII. Esta iglesia siguió en uso hasta el siglo XIII, cuando fue ulteriormente ampliada, probablemente en ocasión de la concesión del fuero a la villa ${ }^{39}$.

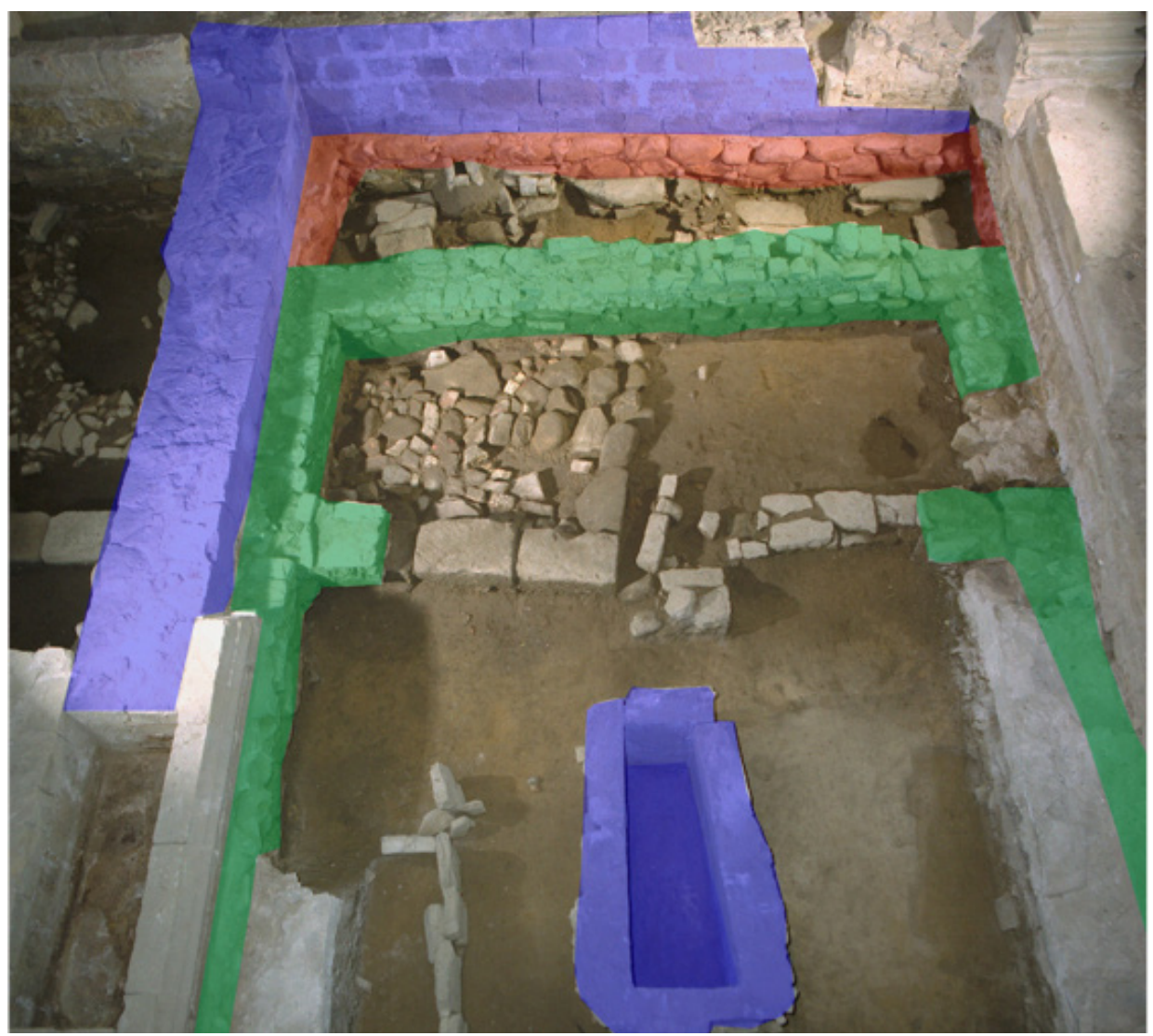

FiguRa 3. Las iglesias altomedievales halladas en el interior de Santa Maria la Real en Zarautz (Guipúzcoa), según A. Ibañez (1. a fase en verde; 2. a fase en rojo; 3. a fase en azul).

38 Ibáñez Echeverría, Álex. Santa María la Real de Zarautz (País Vasco): continuidad y discontinuidad en la ocupación de la costa vasca entre los siglos V a. C. y XIV d. C. San Sebastián: Sociedad de Ciencias Aranzadi, 2009.

39 Ibid. 
Se puede, por lo tanto, concluir que las iglesias «locales» guipuzcoanas conocidas han sido realizadas con técnicas de carpintería o albañilería empleando materiales locales, y han sido edificios modestos que probablemente no destacarían respecto al caserío del entorno.

Este patrón es similar a cuanto se ha documentado en Vizcaya, aunque también hay algunas diferencias. I. García Camino ha catalogado más de un centenar de yacimientos altomedievales en el territorio, generalmente de carácter funerario ${ }^{40}$. Al igual que en Guipúzcoa, tampoco en este territorio se preservan iglesias altomedievales en alzado, pero se ha hallado la planta de un reducido número de edificios eclesiásticos en Finaga, Ranes y Momoitio. Todos estos edificios parecen caracterizarse por su sencillez constructiva, volúmenes reducidos, una distribución simple del espacio y el empleo de técnicas de albañilería consideradas como rudimentarias ${ }^{41}$.

Uno de los mejor conocidos es el ejemplo de San Juan de Momoitio (Garai), atribuida al siglo Ix (fig. 4). En la excavación de la ermita actual se ha hallado una planta

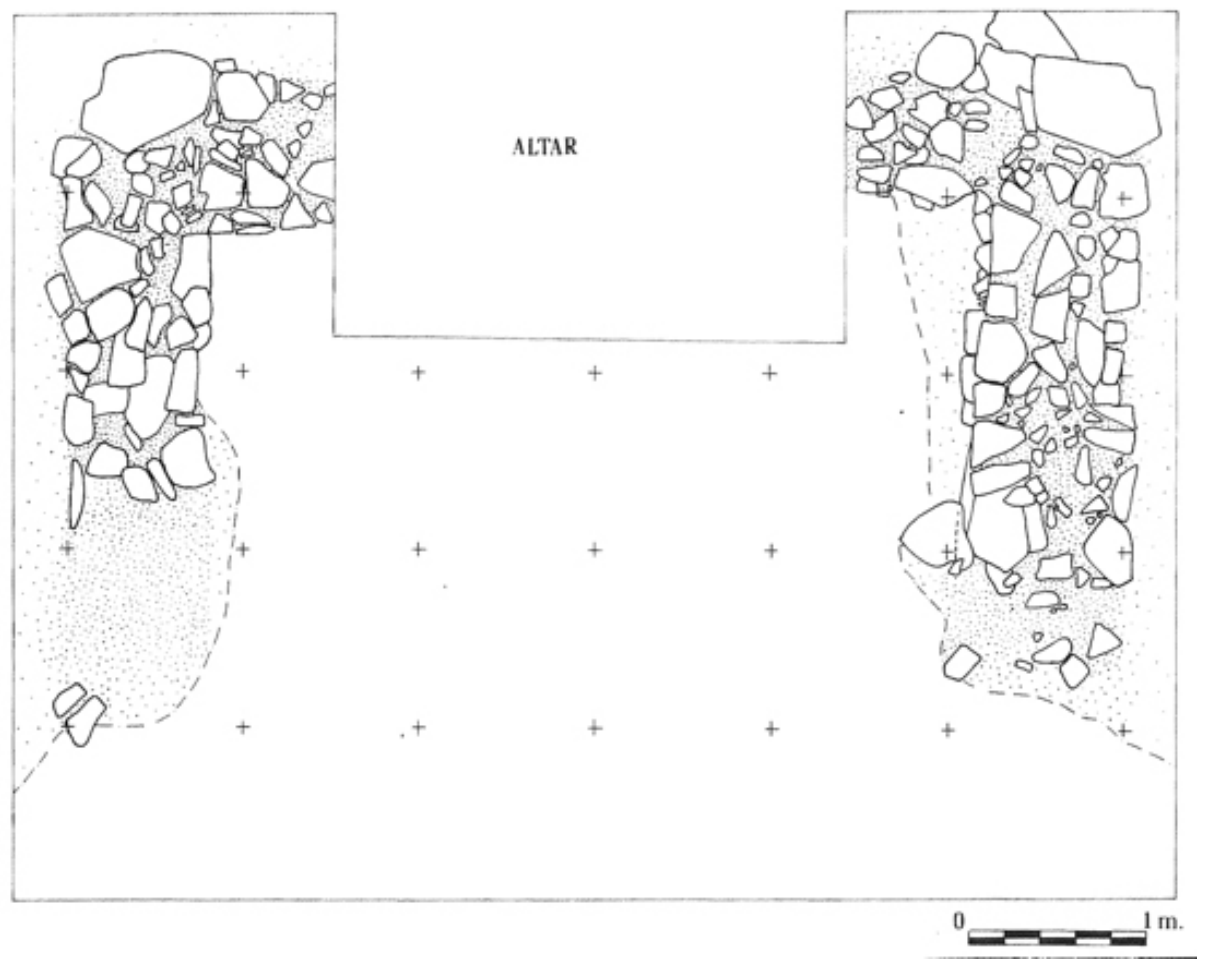

Figura 4. Planta de la iglesia altomedieval de Momoitio (Garai, Vizcaya), según I. Garcia Camino.

40 García Camino, Arqueología y poblamiento en Bizkaia.

41 García Camino, "Zarautz antes que Zarautz”. 
rectangular definida por paramentos de mampostería aparejada con argamasa pobre de cal y esquineras diferenciadas. El muro de cierre occidental debió de ser de madera y, teniendo en cuenta las características y dimensiones del zócalo, se ha sugerido que la cubierta podría ser de materiales vegetales. El templo así delimitado, de 4x3,1 m, está asociado a un cementerio de 113 tumbas que estuvo en uso hasta inicios del siglo XII. Según I. García este tipo de iglesias «locales» habría sido promovido por el campesinado con el fin de tener acceso a toda una serie de fuentes de riqueza que se generaban en torno a estas fundaciones ${ }^{42}$. El hallazgo de estelas, algunos epígrafes y la diversidad de las formas de enterramiento muestran que estas comunidades locales estaban internamente jerarquizadas y recurrían a una diversidad de mecanismos de distinción.

De hecho, no todas las iglesias «locales» eran similares a la de Momoitio. El hallazgo en posición secundaria de un par de decenas de sencillas ventanas monolíticas talladas siguiendo modelos documentados en Asturias es uno de los rasgos más interesantes de la arquitectura de este territorio ${ }^{43}$ (fig. 5 a y 5 b). Se trata de una colección heterogénea de elementos arquitectónicos que han sido fechados en los siglos x y xI y se distribuyen por casi todo el territorio. La reelaboración a escala local de este tipo de vanos no solo debe de ser entendida como un marcador de estatus o de prestigio, sino como un medio a través del cual crear adscripción y pertenencia.

El panorama es más complejo en Álava. En este territorio se conservan en alzado una treintena de iglesias altomedievales y otras son conocidas a través de sus plantas. El excelente estudio de L. Sánchez ha permitido diferenciar una amplia diversidad de sistemas constructivos, habiendo diferenciado obras de cantería realizadas probablemente por artesanos conocedores de soluciones tecnológicas en uso en al-Andalus, respecto a otras construcciones realizadas con soluciones menos sofisticadas ${ }^{44}$. Además, las fuentes escritas y epigráficas preservadas sugieren que en la Alta Edad Media hubo un elevado número de templos, de tal manera que algunas localidades contaban antes del año 1000 con más de una iglesia. Las jerarquías laicas y eclesiásticas parecen ser los principales promotores de fundaciones eclesiásticas en los siglos IX y x, pero tampoco faltan referencias a comunidades locales. En Villambrosa la iglesia fue construida por la comunidad local en el siglo $\mathrm{x}^{45}$, pero también en el sector occidental alavés se intuye la existencia de fundaciones promovidas por líderes aldeanos, como serían algunos de los presbíteros citados en los textos ${ }^{46}$.

\footnotetext{
$42 \quad$ Ibid., p. 378.

43 García Camino, Ińaki; González Cembellín, Juan Manuel y Santana Ezquerra, Alberto. «La arquitectura prerrománica vizcaína». Kobie. Bellas Artes, 1987, vol. 4, pp. 7-38.

44 Sánchez Zuriaurre, Técnicas constructivas medievales.

45 LaRrea CONDE, "Construir iglesias, construir territorio».

46 Quirós Castillo y Santos Salazar, «I villaggi medievali nell'Alto Ebro alla luce delle fonti scritte e dell'archeologia».
} 
PERTENECER Y DIFERENCIARSE. IGLESIAS «LOCALES»

Y AGENCIA CAMPESINA EN EL NOROESTE DE LA PENÍNSULA IBÉRICA JUAN ANTONIO QUIRÓS CASTILLO

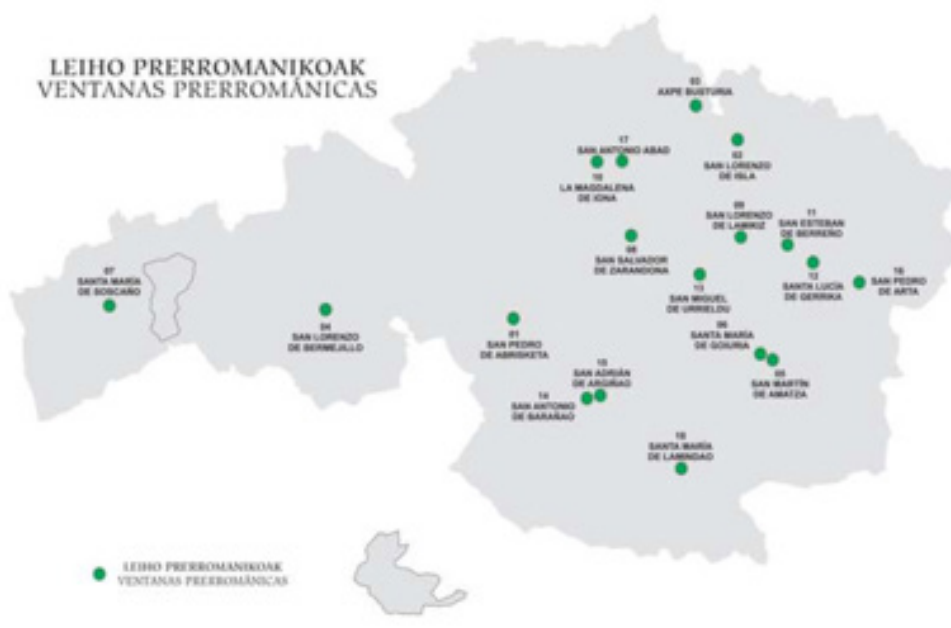

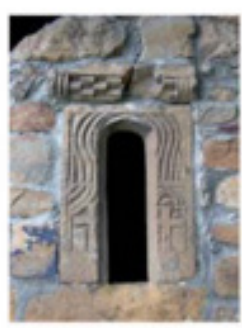

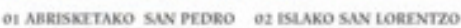

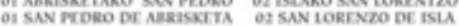

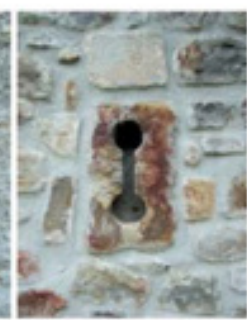

as Axpe-Busrukn

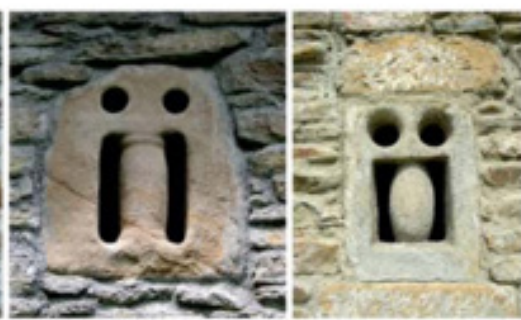

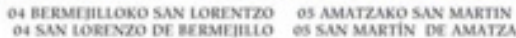
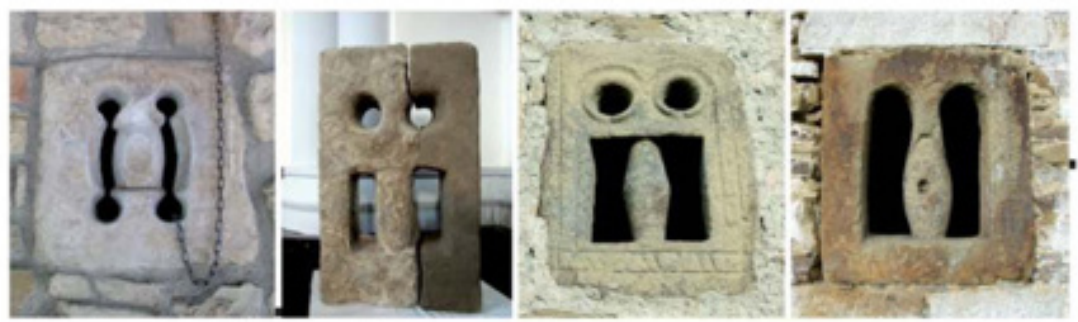

OS COULRIKO ANDRA MERI

7 SOSCANOKO ANDEA MARLA OE ZARANDOUKO SAN SUHATOEZ

LMikrziko siv Lonirizo

Figura 5a. Ventanas prerrománicas halladas en Vizcaya, según Ondare Babesa. 


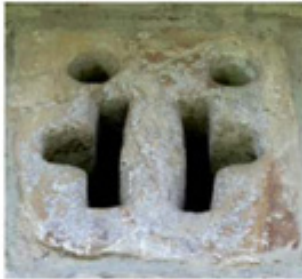

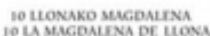

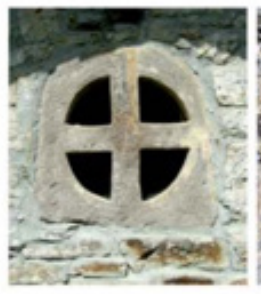

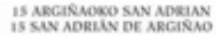

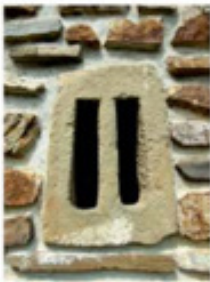

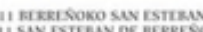
II SAN ESTERAN DE BFRRE

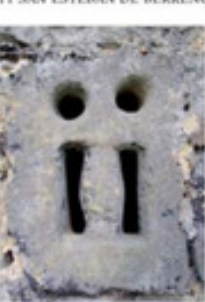

16 AKTAKO SUN FEDRO
i6 SAN FDDEO DE AKTA
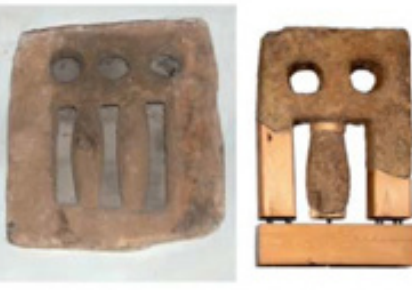

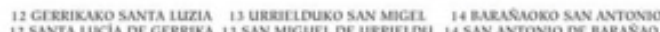

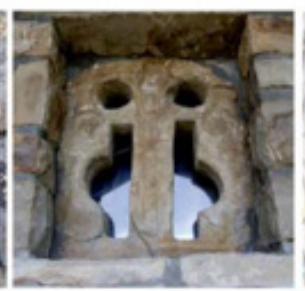

17 SUN ANTONo AENOEA

17 SUN INTOSBO NER
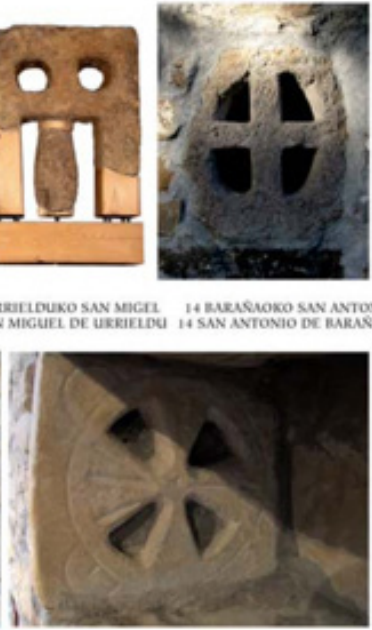

IS LAMNDAOKO NDDEA MAKL

Figura 5b. Ventanas prerrománicas halladas en Vizcaya, según Ondare Babesa.

No obstante, la identificación de los promotores de las iglesias no es una tarea sencilla. Un reducido número de edificios realizados con técnicas sofisticadas, dotados en ocasiones con enterramientos privilegiados, pueden ser adscritos a élites supralocales ${ }^{47}$. Pero en la mayoría de las situaciones esta lectura no es posible. Por contraposición, se considera que los templos erigidos por las comunidades campesinas serían sencillas construcciones de madera o iglesias rupestres ${ }^{48}$. Y aunque en Álava hay algunas referencias documentales a iglesias lignarias ${ }^{49}$, aún no se han identificado en términos materiales.

Quizás un ejemplo de este tipo de construcciones podría ser la iglesia de Santa María de Tejuela (Villanueva de Soportilla, Burgos). El yacimiento de Tejuela no está en Álava, ya que se sitúa en la orilla opuesta del Ebro en el que se localiza el núcleo alavés de Lantarón. Pero indudablemente participa del mismo marco cultural. En el lugar, que fue excavado en el año 1970 por A. del Castillo, se ha hallado una necrópolis altomedieval formada por más de 300 tumbas dispuestas en un promontorio alargado. Nuevas intervenciones realizadas en los últimos años han permitido identificar una aldea a los pies que estuvo en uso desde el siglo viI/viII al XIII/XIV. En una posición preeminente del promontorio se emplaza el zócalo de una construcción rectangular de 9x3,5 m realizado en mampostería trabada con barro de $75 \mathrm{~cm}$ de anchura que ha sido identificada con la

47 SÁNChez Zufiaurre, Técnicas constructivas medievales.

48 Ibid.; García de Cortázar, José Ángel. La construcción de la diócesis de Calahorra en los siglos X a XIII: la iglesia en la organización social del espacio. Logrońo: Instituto de Estudios Riojanos, 2018.

49 Azkarate Garai-Olaun, Agustín y Sánchez Zufiaurre, Leandro. "Las iglesias prefeudales en Álava: cronotipología y articulación espacial». Arqueología de la Arquitectura, 2003, vol. 2, pp. 25-36. 
iglesia aldeana (fig. 6). Un sencillo paramento dividiría el presbiterio de la nave dotada de un simple enlosado. Además, en el presbiterio se ha hallado un hueco destinado al alojamiento del altar. Completa el conjunto un pórtico realizado sobre postes de madera. No obstante, las excavaciones no han permitido establecer la cronología precisa del edificio eclesiástico ni su secuencia ocupacional ${ }^{50}$.

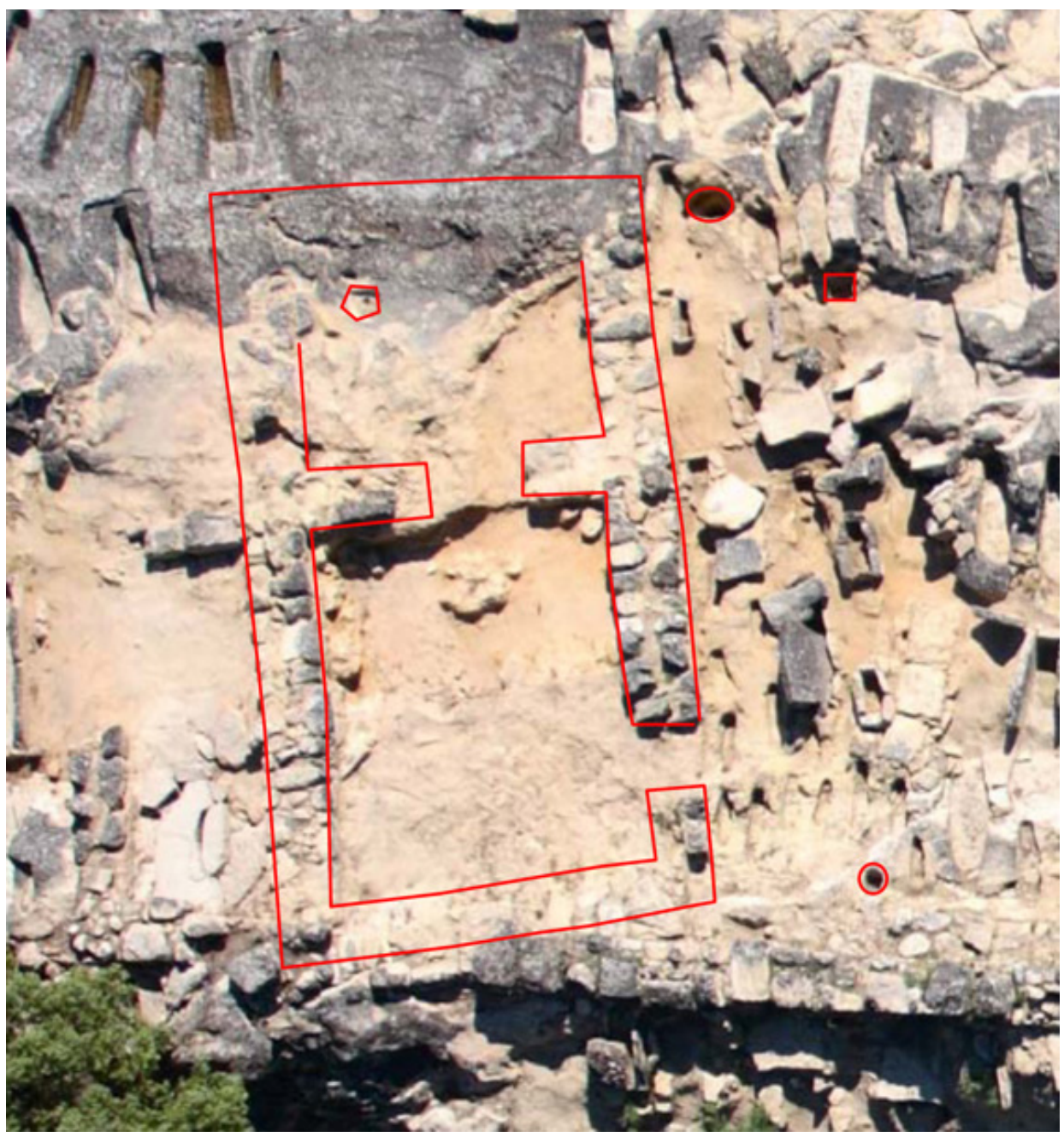

Figura 6. Iglesia de Santa María de Tejuela, según Aratikos 2010.

50 Castillo, Alberto del. Excavaciones altomedievales en las provincias de Soria, Logroño y Burgos. Madrid: Ministerio de Educación y Ciencia, 1972; Aratikos. Excavación arqueológica en la necrópolis de Santa María de Tejuela en Villanueva Soportilla (Bozóo, Burgos). Burgos: Memoria técnica inédita, 2010. 
Sintetizando, las iglesias que han sido atribuidas a la iniciativa de las comunidades locales en el País Vasco se caracterizan por su heterogeneidad. En Guipúzcoa son construcciones de dimensiones modestas, han sido realizadas tanto en piedra como en madera y se han identificado en distintas comarcas. En cambio, las características de las iglesias y de los cementerios hallados en Vizcaya se corresponden con un escenario de mayor competitividad social. El paisaje social es aún diferente en la vertiente mediterránea alavesa, donde se articulan complejas formas de representación y de construcción de las jerarquías en las sociedades locales recurriendo a soluciones arquitectónicas y lenguajes de distinción ausentes en las otras dos provincias. Paradójicamente, en este territorio no se reconocen con facilidad las iglesias «locales». Frente a esta diversidad, en términos funcionales todas ellas tienen un carácter funerario y generan su propio camposanto.

\subsection{Asturias}

También en Asturias parece existir una relación inversa entre el grado de complejidad social y la aparente invisibilidad de las iglesias «locales». Las iglesias identificadas y atribuidas a las comunidades locales se localizan preferentemente en espacios periféricos respecto a los núcleos en los que se concentran las construcciones conocidas bajo el epígrafe de «arquitectura prerrománica asturiana». El estudio de la arquitectura áulica, monástica o vinculada de distintas formas a la actividad de los monarcas y los magnates del reino ha conocido un notable desarrollo en el último cuarto de siglo, generando una abundante producción bibliográfica. Pero también han empezado a ser reconocidas algunas construcciones que se han atribuido a las comunidades locales ${ }^{51}$. Aunque las fuentes escritas mencionan la existencia de un centenar de iglesias en la región, en ningún caso se mencionan expresamente fundaciones promovidas por las comunidades locales o por líderes aldeanos. Por ello, todas las atribuciones han sido realizadas a partir de las excavaciones o los estudios arqueológicos realizados en templos como los de Riomiera, Tina, Plecín, Serrapio, Veigas o Arbazal ${ }^{52}$. En esta ocasión nos centraremos únicamente en tres ejemplos.

Desde que en el año 1995 C. García de Castro publicase su exhaustiva tesis doctoral sugiriendo que el edificio alargado de unos 7x3,5 m adosado a la actual parroquia de la aldea asturiana de Arbazal podría ser una iglesia de una comunidad aldeana, la mayor parte de los autores han asumido esta atribución ${ }^{53}$. Ello se debe a que se trata de un prototipo de cómo nos imaginamos que podría ser una iglesia altomedieval promovida por una comunidad local (fig. 7). Es una construcción simple, realizada en mampostería sin esquineras en sillar, y con una cabecera diferenciada respecto a la nave. El contraste

51 Caballero Zoreda, Luis; Mateos Cruz, Pedro y García de Castro Valdés, César. Asturias entre visigodos y mozárabes. Madrid: Consejo Superior de Investigaciones Científicas, 2012; GARCía de CASTRo VAldÉs, Arqueología cristiana de la Alta Edad Media en Asturias; Arias PÁRAmo, Enciclopedia del prerrománico en Asturias; Utrero Agudo, Iglesias altomedievales en Asturias. Trea, 2010

52 García Álvarez-Busto, Alejandro y Muñız López, Iván. Arqueología medieval en Asturias. Gijón:

53 García de Castro Valdés, Arqueología cristiana de la Alta Edad Media en Asturias, pp. 392-394. 
con San Salvador de Valdediós, situada a menos de un kilómetro en línea recta, es descomunal. La iglesia de Arbazal ha sido fechada en los siglos viII-X a partir de las similitudes que presenta con otros ejemplos conservados en el Pirineo catalán. No obstante, en ausencia de excavaciones arqueológicas no es posible obtener conclusiones definitivas acerca de su funcionalidad y cronología.

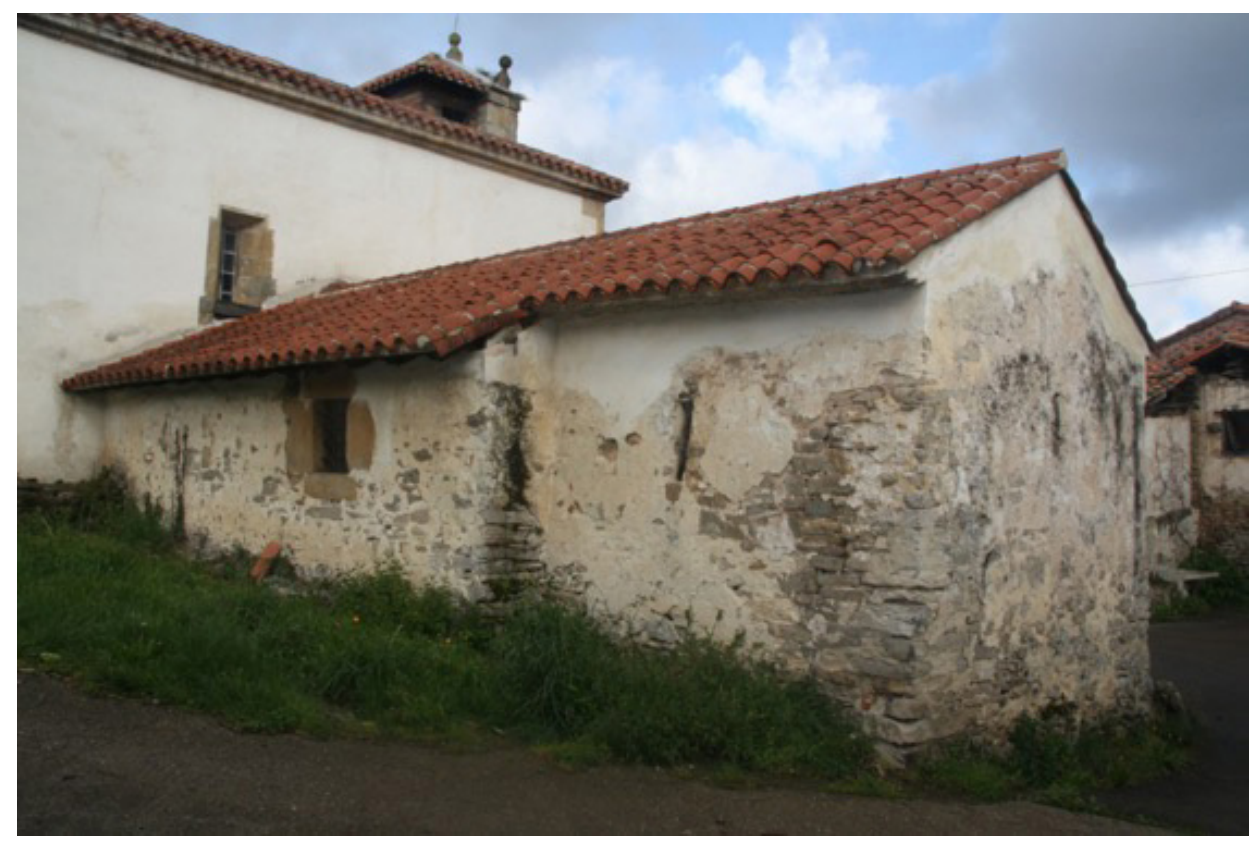

Figura 7. Iglesia de Santa María de Arbazal, Villaviciosa.

Los restantes ejemplos de iglesias «locales» reconocidos en Asturias han sido objeto de intervenciones arqueológicas preventivas. Son particularmente interesantes los hallazgos realizados en el municipio de Aller. Este es el caso de la iglesia de San Juan de Riomiera, antecedente de la actual parroquia de San Juan de Santibáńez (Aller), que fue reconocida en ocasión de la ampliación de una carretera ${ }^{54}$. La planta del edificio es sencilla y similar a la de Arbazal: cabecera rectangular de 4x5 m y nave alargada de unos 8,5x6 m de longitud (fig. 8). El edificio ha sido realizado en mampostería de cal, sin esquineras diferenciadas ni engrosamiento del ábside propio de las cabeceras abovedadas. Los paramentos externos estaban cubiertos por un revestimiento que ocultaba el aparejo y el pavimento estaba realizado por un enlosado irregular. La construcción ha sido fechada entre los siglos IX-X y se habría mantenido en uso hasta el siglo Xv. En el interior y en proximidad de la iglesia se han identificado una treintena de tumbas pertenecientes a dos

54 Arias Páramo, Enciclopedia del prerrománico en Asturias. 
fases. Se han asignado a la primera fase once sepulturas, una de las cuales se ha fechado en los siglos V-VII. En cambio, la segunda etapa es coetánea al edificio religioso ${ }^{55}$.

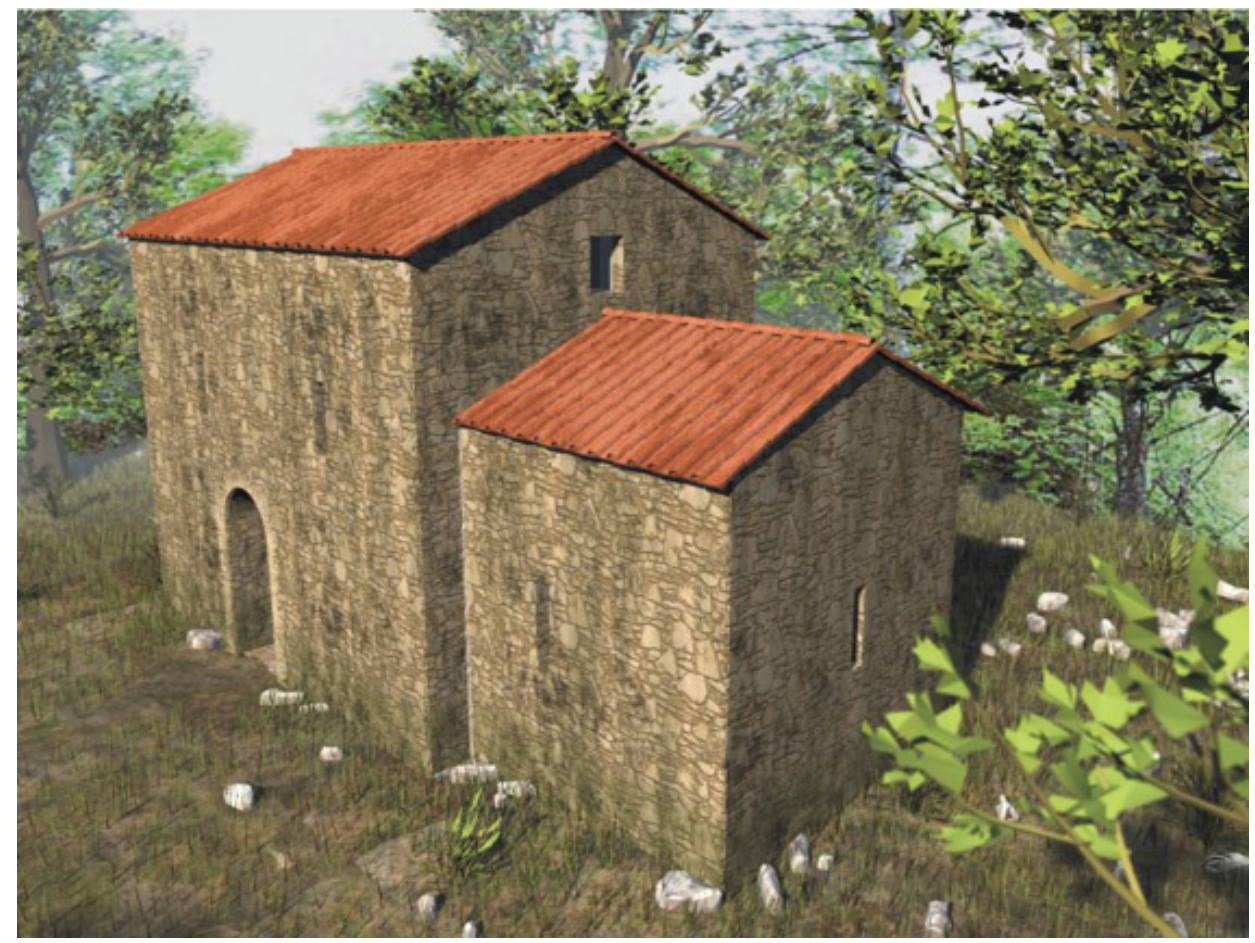

Figura 8. Reconstrucción de la iglesia de San Juan de Riomiera (Aller), según O. Requejo.

A unos $8 \mathrm{~km}$ hacia el NO se encuentra la iglesia de San Vicente de Serrapio (Aller), edificio construido entre finales del siglo XII y el siglo XIII. En la sacristía de la iglesia se conserva, además de una inscripción romana dedicada a Júpiter, un epígrafe fundacional que recuerda que la «basilica» fue realizada por el presbítero Gagius en julio del año 944. También se menciona a un cierto Mellitus como autor de la obra ${ }^{56}$. Las excavaciones preventivas realizadas en ocasión de la rehabilitación del templo han permitido documentar una secuencia ocupacional y constructiva de notable interés ${ }^{57}$. La primera de las cinco fases reconocidas se corresponde con un paramento en mampostería montada

55 Requejo Pagés, Otilia; Arca Miguélez, María Cristina; Arias PÁramo, Lorenzo et al. "Descubrimiento de la antigua iglesia de San Juan de Riomiera (Collanzo, Aller)». En Excavaciones arqueológicas en Asturias: 1999-2002. Oviedo: Principado de Asturias, 2007, pp. 347-356.

56 Diego Santos, Inscripciones medievales de Asturias.

57 Requejo Pagés, Otilia. «II fase de restauración en la iglesia de San Vicente de Serrapio, Aller (1991-1992): resultados arqueológicos». En Excavaciones arqueológicas en Asturias: 1991-94. Oviedo: Principado de Asturias, 1995, pp. 293-296. 
con mortero de cal de cronología imprecisa. Se atribuye a la Alta Edad Media una serie de enterramientos, sin que se haya podido hallar un templo asociado. La tercera fase ha sido identificada con la iglesia fundada por Gagius en el siglo x, y su construcción ha comportado la destrucción de alguna de las tumbas anteriores. Este edificio reutiliza el paramento de la fase más antigua, y sus cimientos han sido realizados con cantos de río aparejados con arcilla. Asociada a esta construcción se ha identificado un cementerio superpuesto al anterior. Con posterioridad se construyó la iglesia actual en dos etapas y se dispusieron otros enterramientos. Aunque la intervención ha sido muy limitada, ha mostrado que la iglesia altomedieval fue construida sobre una necrópolis previa.

Los restantes ejemplos que han sido atribuidos a comunidades locales, esto es, las iglesias de Santa María de Tina, San Pedro de Plecín y quizás las de San Pedro de Arrojo y San Andrés de Veigas, presentan características bastante similares a estos ejemplos.

La creación del reino astur y su definición ideológica ha determinado que la construcción de iglesias haya constituido una prioridad de los monarcas y su entorno, dando lugar a una producción dotada de un lenguaje arquitectónico propio y reconocible. La existencia de un mercado de materiales reutilizados y de talleres estables que han cultivado canteras nuevas son solo algunos de los rasgos que definen estos edificios ${ }^{58}$. Pero la irradiación de este lenguaje no se limitó únicamente a las fundaciones regias y de los magnates del reino. En un trabajo previo hemos sugerido que la docena de ventanas monolíticas empleadas en varios templos rurales de la región podrían proceder de uno o más talleres centralizados (fig. 9). Teniendo en cuenta los contextos en los que se emplean, se podría pensar que estos vanos, más estandarizados que los vizcaínos, han sido utilizados como estrategia de distinción por parte de élites locales o líderes aldeanos promotores de iglesias "locales» ${ }^{59}$. Mediante este recurso se construiría un discurso político de adscripción y participación a un programa político y religioso liderado por la monarquía en clave local, tomando para ello como referencia los prototipos formales de la arquitectura áulica. Se trata, por lo tanto, de un mecanismo de construcción del orden social análogo al que hemos visto en el caso vizcaíno.

Sintetizando, las iglesias adscritas a las comunidades locales o a sus líderes en Asturias presentan rasgos bastante más uniformes que los observados en el País Vasco. En casi todos los casos tenemos constancia de que han sido levantadas sobre espacios funerarios previos; todas ellas generan cementerios; sus rasgos técnicos, compositivos, formales y dimensionales presentan analogías entre sí; parecen haber sido construidas en piedra y, en ocasiones, parece que están recurriendo a reelaboraciones de símbolos y soluciones presentes en la arquitectura regia.

58 Utrero Agudo, Iglesias altomedievales en Asturias.

59 Quirós Castillo y Fernández Mier, «Para una historia social de la arquitectura monumental». 


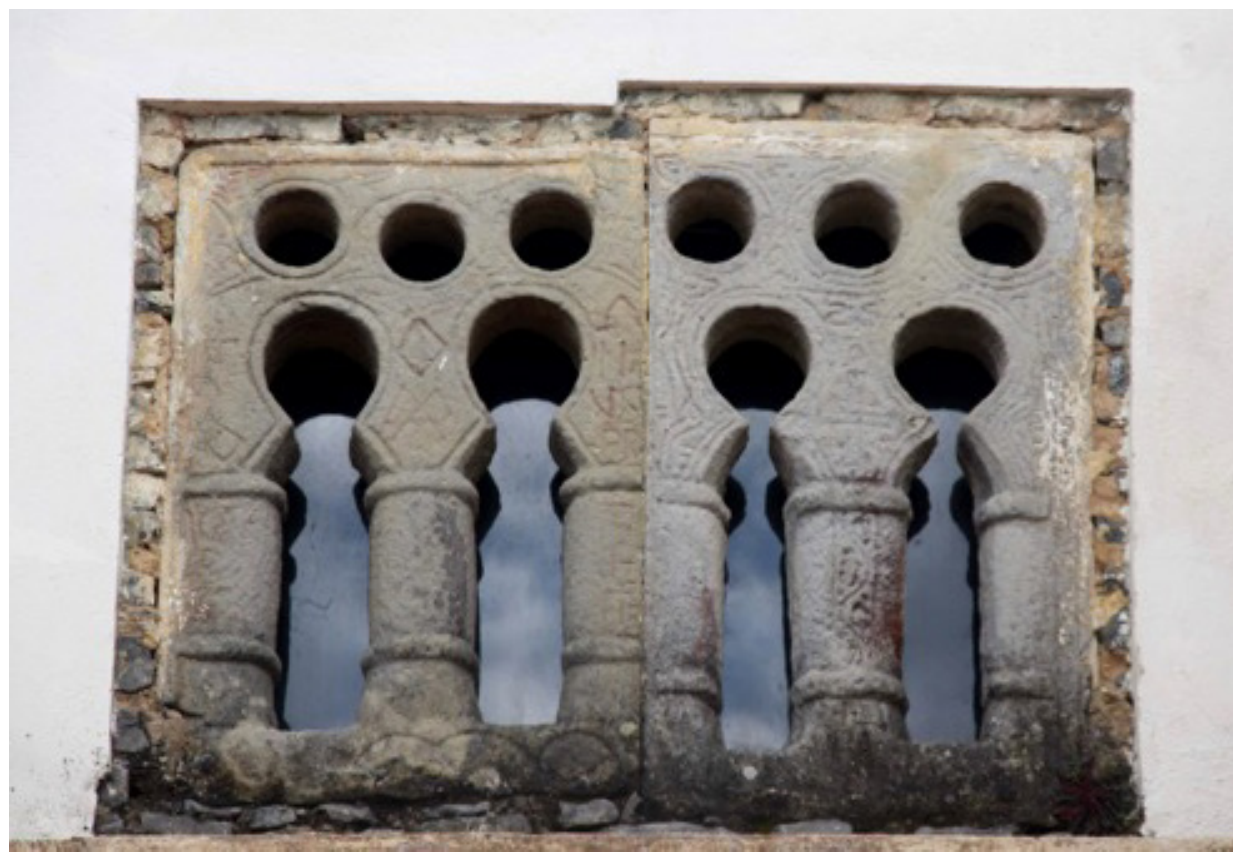

Figura 9. Ventanas monoliticas de Santiago de Sariego (Sariego).

\section{IgLESIAS «LOCALES» Y AGENCIA CAMPESINA}

Gracias a las aportaciones realizadas por la arqueología y la historia de las sociedades locales, un número creciente de autores piensan que gran parte de las aldeas altomedievales del norte peninsular debieron contar con una o varias iglesias, capillas u oratorios ${ }^{60}$. Es decir, los magros inventarios con los que se han construido las síntesis de los estilos arquitectónicos altomedievales no son representativos de la diversidad y heterogeneidad de las fundaciones eclesiásticas que han poblado los paisajes rurales del norte peninsular. El estudio de las iglesias «locales» plantea muchos retos de orden epistemológico, metodológico y heurístico debido a su carácter polifuncional. En este trabajo se analizan desde un prisma muy concreto: las iglesias «locales» como medio para indagar la agencia del campesinado. Para ello se considerarán únicamente tres aspectos: las tecnologías constructivas, la relación entre iglesias «locales» y espacios funerarios,

60 García de Cortázar, La construcción de la diócesis de Calahorra; Sánchez Pardo, Torre Llorca y Fernández Ferreiro, «Élites, arquitectura y fundación de iglesias en Galicia». También en Aquitania se ha llegado a la misma conclusión; ver FARAvel, Sylvie. "Bilan des recherches sur les origines de la paroisse en Aquitaine (IV $\mathrm{I}^{\mathrm{e}}$ siècle)». En Aux origines de la paroisse rurale en Gaule méridionale (IV-IX siècles). Paris: Errance, 2005, pp. 150-158. 
y el destino de las iglesias «locales» en el proceso de la formación de las parroquias plenomedievales.

\subsection{Tecnología y representación social}

El carácter liminal de la Alta Edad Media respecto a dos períodos tan bien caracterizados como son la Antigüedad y la Edad Media ha hecho que los estudios sobre este período hayan estado muy condicionados por ciertos apriorismos. Es cierto que el primitivismo económico y la simplificación social han sido prácticamente erradicados de las narrativas dominantes, pero todavía subsisten ciertas caracterizaciones problemáticas, como es la identificación entre sociedades campesinas y pobreza económica. Una consecuencia directa de su precariedad económica sería la simplicidad de la cultura material, cuya expresión más evidente sería la notable difusión de los objetos y las arquitecturas realizadas en madera. No debe resultar por lo tanto extrańo que la mayor parte de los autores que han intentado caracterizar las iglesias construidas por las comunidades campesinas y los líderes aldeanos hayan sugerido que podrían o deberían ser de madera, consideradas como «menos costosas». Solo las élites tendrían suficientes recursos para promover construcciones sólidas realizadas en piedra. Por lo tanto, el proceso de petrificación de la arquitectura religiosa que tuvo lugar en el período «románico» habría supuesto un "progreso" como reflejo de la existencia de una mayor capacidad de inversión ${ }^{61}$. Sin embargo, los ejemplos presentados en este trabajo proponen un cuadro mucho más articulado. No hay duda de que algunas iglesias «locales» han sido realizadas únicamente en madera, otras en técnicas mixtas, pero también hay ejemplos de construcciones realizadas en mampostería y otras tecnologías. Y aunque se observan diferencias importantes entre el País Vasco y Asturias, no es demasiado sencillo intentar explicar adecuadamente estas diferencias: ¿eran más «ricos» los campesinos del solar astur respecto a los del País Vasco?, ¿eran más «poderosas» las élites aldeanas de una región respecto a otra?, ¿por qué se recurre a una determinada tecnología?

En ambas regiones se han hallado arquitecturas domésticas realizadas en madera y en técnicas mixtas tanto en contextos rurales como $\operatorname{urbanos}^{62}$. Y, aunque los hallazgos de arquitecturas lignarias parecen ser más numerosos en el País Vasco que en Asturias,

${ }_{61}$ La bibliografía es abundantísima. Ver SÁNCHEZ Zufiaurre, Técnicas constructivas medievales; GARCÍA DE CoRTÁZAR, La construcción de la diócesis de Calahorra. El paso de la madera a la piedra ha sido descrito como un "progreso» de las técnicas de construcción frente a las «infraconstrucciones» campesinas. Ver BonNASSIE, Pierre. «Conclusion». En Villages pyrénéens: morphogenèse d'un habitat de montagne. Toulouse: CNRS, 2001, pp. 283-297.

62 En Asturias se pueden citar, entre otros, los casos de Oviedo (Gutiérrez GonZález, José Avelino. "Arqueología de la temprana Edad Media en Asturias: sobre los orígenes antiguos de Oviedo». En Arqueología de época histórica en Asturias. Oviedo: RIDEA, 2018, pp. 13-46) o el de Veigas en Somiedo (MSArqueo. Memoria técnica de la excavación arqueológica de la necrópolis de San Andrés de Veigas. Oviedo: Memoria inédita, 2012). En el País Vasco los ejemplos de Vitoria-Gasteiz (Azkarate Garai-Olaun, Agustín y Solaun BustinZA, José Luis. «Tipologías domésticas y técnicas constructivas en la primitiva Gasteiz (País Vasco) durante los siglos viI al XII d. C». Arqueología de la Arquitectura, 2013, vol. 9, pp. 103-128) y Zaballa (Quirós Castillo, Arqueología del campesinado medieval) son algunos de los más representativos. 
esta diferencia puede ser el reflejo de dos trayectorias investigadoras distintas. En todo caso, en el País Vasco se han hallado arquitecturas realizadas sobre postes de madera dotadas de un alto nivel de sofisticación y complejidad, como son las longhouses halladas en yacimientos como el de Gasteiz o el de Aistra, que han sido identificadas en ambos casos como construcciones pertenecientes a élites sociales. En particular en este último yacimiento estas construcciones parecen haber constituido el núcleo espacial y político sobre el que se ha articulado la vida social. Por eso resulta interesante constatar que hay una correspondencia entre el abandono de la longhouse principal y la construcción hacia el 950 de una iglesia propia realizada con sillares de arenisca nuevos. Se puede sugerir, por lo tanto, que se produjo una transferencia del capital simbólico del edificio lignario a la iglesia pétrea ${ }^{63}$.

La existencia de talleres especializados basados en la tecnología de la madera no es fenómeno exclusivo de la Alta Edad Media. La iglesia parroquial de San Ildefonso de la villa de Vitoria, fundada hacia el año 1256, fue construida enteramente en madera. Solamente en el siglo Xvi fue reemplazada por un nuevo templo de piedra ${ }^{64}$. Además, no se trata de casos aislados. En numerosas regiones europeas se conocen iglesias realizadas sobre postes de madera, tanto en contextos locales como en núcleos de carácter aristocrático, como son los manor ingleses ${ }^{65}$.

Pierre Lemonnier ha sostenido que un enfoque economicista y productivista no es suficiente para explicar el significado profundo de las tecnologías y los artefactos. Según este autor los procesos físicos y mentales mediante los cuales se produce la materialidad están socialmente determinados ${ }^{66}$. Dicho en otras palabras, la cultura material no es un reflejo pasivo de un estatus económico o de una noción universal de valor, sino que es el resultado de la toma de decisiones orientada a construir activamente una realidad y un orden social ${ }^{67}$. Adoptando esta perspectiva, la pregunta ya no es si las comunidades locales construyen en piedra, en madera, con formas abovedadas o compartimentadas, con material reutilizado o nuevo en función de su capacidad de inversión. Más bien hay que preguntarse qué considera aceptable y adecuado un determinado colectivo en términos de tecnologías, morfologías y funcionalidades a la hora de realizar un edificio de culto ${ }^{68}$. Y evidentemente dar respuesta a estos interrogantes exige centrarse en los contextos locales y en las audiencias que hacen significativo el empleo de una u otra solución.

63 Quirós Castillo, Juan Antonio. «Longhouses, biografía de la casa y complejidad social en el noroeste peninsular en la Alta Edad Media». Arqueología de la Arquitectura, 2017, vol. 14.

64 García Gómez, Ismael. Vitoria-Gasteiz y su hinterland. Evolución de un sistema urbano entre los siglos XI y XV. Bilbao: Universidad del País Vasco, 2017.

${ }_{65}$ Chavarría, Alexandra. Archeologia delle chiese: dalle origini all'anno Mille. Roma: Carocci, 2009. Sobre las iglesias en los manor anglosajones ver: Blair, The Church in Anglo-Saxon society. En Suiza y en las regiones italianas de Lombardía y Trentino-Alto-Adige han sido halladas varias iglesias y oratorios funerarios lignarias atribuidas al evergetismo aristocrático (ver, por ejemplo, Brogiolo, Gian Pietro. "San Tomé di Carvico. Archeologia di una chiesa altomedievale». En Carvico alle pendici del Monte Canto. Milano: Comune di Carvico, 2016, pp. 161-223.)

66 Lemonnier, Pierre. Elements for an anthropology of technology. Ann Arbor: Museum of Anthropology, University of Michigan, 1992.

67 HodDer, Interpretación en arqueología.

68 Rapoport, Amos. Vivienda y cultura. Barcelona: Gustavo Gili, 1972. 
La iglesia de San Pedro de Iromendi probablemente no se diferenciaba mucho de las construcciones domésticas del entorno, lo que permitiría pensar que sería un artefacto inclusivo, orientado a tejer vínculos de pertenencia y de identidad relacional en una comunidad, probablemente, dotada de una fuerte cohesión interna. Al contrario, iglesias técnicamente sofisticadas y ejecutadas por canteros itinerantes probablemente procedentes de lugares lejanos, como son los ejemplos alaveses de San Román de Tobillas o San Julián de Aistra, serían instrumentos de distinción, segregación y construcción de relaciones asimétricas potenciando las identidades individuales. Se puede sugerir, de hecho, que los mecanismos de afirmación de estatus son más visibles precisamente cuando el equilibrio social es más inestable, cuestionado o experimental.

Pero caben otras soluciones. El 16 de julio del año 903 el obispo de Urgel, Nantigís, consagró la iglesia de Sant Andreu de Sagàs en presencia del sacerdote Galindo y todos los habitantes de la parroquia, que la habían construido. Esta es una de las pocas iglesias catalanas en las que una intervención arqueológica ha permitido restituir la planta del edificio altomedieval que ha sido promovido por una comunidad de vecinos, liderados en este caso por un eclesiástico local. Tanto en términos dimensionales como constructivos esta iglesia presenta grandes analogías con otros templos coetáneos fundados por condes, aristócratas y élites supralocales ${ }^{69}$. En otras palabras, no parece que sea posible identificar en este territorio los sujetos sociales en función de las tecnologías y las morfologías empleadas. Hasta un cierto punto hay un estándar constructivo considerado aceptable a la hora de fundar una iglesia «local».

En cambio, en otras ocasiones la petrificación de la arquitectura religiosa ha sido merecedora de ser conmemorada y explicitada. Este es el caso de la construcción en el año 1087 de la burgalesa iglesia de San Miguel de Neila, fundada por el abad Nuño y realizada por el maestro Munio Sancho. El epígrafe conmemorativo recuerda cómo el abad fundabit ecclesias et labor a petra cale ${ }^{70}$. Este ejemplo evoca más un proceso de monumentalización que de mera petrificación, que son prácticas que no siempre van necesariamente de la mano.

De todo lo seńalado se puede concluir que la madera, el barro y otras tecnologías constructivas poco sofisticadas no son necesariamente los materiales de todas las comunidades campesinas. Ello es debido a que la inversión de «excedentes» o fondos ceremoniales $^{71}$ no refleja de forma directa la «riqueza» de los sujetos ni el «valor» que se les pueda atribuir hoy en día. Las técnicas y, en general, las soluciones arquitectónicas adoptadas a la hora de construir un artefacto como es una iglesia local son el resultado de un proceso de toma de decisiones embebidas en prácticas sociales significativas en un contexto específico.

69 Baraut, Cebrià. «Les actes de consagracions d'esglésies del bisbat d'Urgell (segles IX-XII)». Urgellia, 1978, vol. 1, pp. 11-182. Riu i Barrera, Eduard. Memòria de l'excavació del temple de Sant Andreu de Sagàs. Barcelona: Generalitat de Catalunya, 1986.

70 Castresana López, Corpus Inscriptionum Christianarum et Mediaevalium Provinciae Burgensis.

71 La noción de «fondo ceremonial» es de WoLf, Los campesinos. 


\subsection{Iglesias, cementerios y asentamientos}

Puesto que la mayor parte de las excavaciones realizadas en las iglesias altomedievales del norte peninsular son de carácter preventivo, la mayor parte de ellas se han limitado a indagar el interior o el inmediato exterior de las construcciones. Como consecuencia de ello resulta difícil definir su funcionalidad y la relación con otros componentes poblacionales. Por otro lado, el peso que ha tenido en el noroeste peninsular el paradigma de la despoblación/repoblación, reemplazado posteriormente por el de la colonización ${ }^{72}$, explica el interés que ha despertado conocer el papel que han tenido las iglesias en la creación de los lugares habitados en la Alta Edad Media. Y, aunque algunos consideran ocioso establecer la prelación entre iglesias locales y la morfología de los lugares habitados, este es un instrumento poderoso para identificar agentes y prácticas sociales.

Debemos a geógrafos como R. D. Sack una noción de territorialidad de carácter relacional que ha sido aplicada con éxito a la caracterización de las sociedades altomedievales. Según este autor la noción de territorio no se debe declinar necesariamente a partir de límites espaciales perfectamente definidos y acotados, cuanto en función de prácticas y relaciones sociales significativas que se establecen en un determinado espacio ${ }^{73}$. Esta noción de territorialidad es muy apropiada para acercarse a las distintas escalas de las comunidades políticas altomedievales caracterizadas por el policentrismo y la dispersión funcional ${ }^{74}$. Los trabajos arqueológicos realizados en los últimos años han mostrado la superposición, complejidad y diversidad de las territorialidades locales en este período. En Álava, por ejemplo, se han documentado asentamientos sin cementerios, cementerios sin asentamientos, necrópolis sin iglesias, asentamientos con cementerios y con iglesias, realidades polinucleares y otras variantes. Cualquier intento de establecer una relación simple entre asentamiento, cementerio comunitario e iglesia «local» está destinado al fracaso $^{75}$. Cada uno de estos elementos genera formas comunitarias y territorialidades que se anidan para crear paisajes sociales muy heterogéneos. Solo la parroquia y los concejos rurales plenomedievales contribuirán de forma decisiva a crear territorialidades delimitadas que han perdurado hasta nuestros días.

Teniendo en cuenta estos antecedentes, ¿en qué contextos sociales y espaciales se fundan las iglesias «locales»?, ¿qué funciones desempeñan?, ¿hay un patrón común

72 Escalona, Julio y Martín Viso, Iñaki. «The Life and Death of an Historiographical Folly: The Early Medieval Depopulation and Repopulation of the Duero Basin». En Beyond the Reconquista: New Directions in the History of Medieval Iberia (711-1085). Leiden: Brill, 2020, pp. 21-51.

73 SACK, Robert David. Human territoriality: its theory and history. Cambridge: Cambridge University Press, 1986. Ver asimismo Brookes, Stuart y Reynolds, Andrew. "Territoriality and Social Stratification: The Relationship between Neighbourhood and Polity in Anglo-Saxon England». En Polity and Neighbourhood in Early Medieval Europe. Turnhout: Brepols, 2019, pp. 267-304.

74 Ver ahora Quirós Castillo, Juan Antonio. "Arqueología de los condados castellanos. Sociedades locales y prácticas políticas en Lantarón (siglos IX-X)». SPAL: Revista de Prehistoria y Arqueología de la Universidad de Sevilla, 2020, en prensa.

75 Y la territorialidad se haría aún más compleja si se tomase en consideración la articulación de los espacios de producción agraria y ganadera. Un trabajo de referencia sobre la formación de los territorios parroquiales en la Edad Media es el de Zadora-Rio, Elisabeth. Des paroisses de Touraine aux communes d'Indreet-Loire: La formation des territoires. Tours: Ferac Editions, 2008. 
reconocible en los dos sectores estudiados? Hay algunos rasgos comunes, ya que todas las iglesias «locales» tienen un carácter funerario y en ningún caso se ha identificado una función bautismal. Pero también hay importantes diferencias de carácter regional. En Asturias las iglesias de Riomiera, Serrapio, Abamia y, quizás, Veigas y Plecín se ubican sobre cementerios previos, que en ocasiones se pueden remontar a los siglos V-VII. En cambio, en el País Vasco Iromendi, Zarautz, Getaria, Momoitio y Tejuela generan un nuevo espacio funerario, aunque en ocasiones reocupan lugares que fueron habitados en época premedieval $^{76}$. Al contrario, las iglesias promovidas por las élites en Asturias parecen ser disruptivas respecto al paisaje previo, generando un nuevo camposanto ${ }^{77}$, mientras que en el País Vasco se ubican sobre lugares ya habitados. Estas diferencias son importantes porque permiten argumentar que las iglesias han tenido funciones y significados distintos en cada territorio ${ }^{78}$.

Una abundante producción científica de carácter antropológico ha mostrado que los cementerios no son un mero receptáculo pasivo de los enterramientos de los miembros de una comunidad, sino un espacio social en el que se construye una comunidad que no ha de basarse necesariamente en la vecindad ${ }^{79}$. Puesto que en la Alta Edad Media es posible elegir el lugar de enterramiento y en torno a los cementerios comunitarios se entretejen complejas prácticas de exclusión, distinción y pertenencia, hay que esperar que no todos los habitantes de una localidad se entierren necesariamente en él. En consecuencia, la construcción de una iglesia privada de carácter funerario no es un mero índice de "cristianización», sino el fruto de una voluntad expresa de generar a través de un artefacto legitimador un determinado orden social. De hecho, hay que pensar que la construcción de una nueva iglesia habría generado tensiones, alianzas, competición y relaciones asimétricas que moldearían intensamente las sociedades locales.

En el caso de Asturias podría sugerirse que la fundación de iglesias propias sobre espacios funerarios habría sido un mecanismo de refuerzo y/o reelaboración de la identidad relacional, así como un canal de participación en unos marcos ideológicos gestados por el poder central y la jerarquía eclesiástica. En cambio, en el País Vasco el binomio iglesia «local»-cementerio colectivo tiene un carácter fundante, y de hecho parece haber una coincidencia cronológica entre la creación de las iglesias «locales» y las aldeas. Por otro lado, este no fue el único expediente utilizado por las comunidades locales para reforzar la identidad relacional, y en el País Vasco hay necrópolis sin iglesias fechadas en los siglos VIII-X que, en cambio, son desconocidas en Asturias.

A su vez, las iglesias realizadas por las élites supralocales en las aldeas del País Vasco son verdaderos caballos de Troya puesto que generan relaciones asimétricas y formas de apropiación de derechos desde dentro de las comunidades locales. Esta es la razón por

76 No obstante, estas tendencias admiten excepciones, como es el caso vizcaíno de Finaga.

77 García Álvarez-Busto, Alejandro. «Iglesias, cementerios, poblamiento y ordenación social y territorial en el Reino de Asturias». Anejos de Nailos: Estudios Interdisciplinares de Arqueología, 2019, vol. 5, pp. 483-512, p. 495.

78 En este sentido es muy interesante el caso de Islandia, Vésteinsson, Orri; SveinbjörnsdótTir, Árný; GestsDótTiR, Hildur et al. «Dating religious change: Pagan and Christian in Viking Age Iceland». Journal of Social Archaeology, 2019, vol. 19, n. ${ }^{\circ}$ 2, pp. 162-180.

79 Parker Pearson, Michael. The archaeology of death and burial. Stroud: Sutton, 2003. 
la que se produce una acumulación masiva de capital simbólico a través del recurso a fábricas regulares destinadas a quedar en vista, o la realización de enterramientos privilegiados en su interior, como los que se han hallado en Tobillas o en Ullibarri Arana, o en el exterior, como sucede en Aistra ${ }^{80}$.

En definitiva, las iglesias «locales» generan cohesión e integración, pero también articulan estrategias de distinción naturalizando la desigualdad intrínseca de las comunidades. Las diferencias que se han observado entre las iglesias de Asturias y el País Vasco en términos de tecnologías, soluciones arquitectónicas, relación con los cementerios, formas de conmemoración, prácticas sociales, etc., podrían estar mostrando una diversidad de las sociedades locales y de los contextos sociopolíticos en las que operan.

\subsection{Más allá del año mil. Las iglesias locales en el proceso de parroquialización}

¿Por qué las iglesias «locales» son tan escurridizas o incluso invisibles en términos materiales? En buena medida esta pregunta solo puede ser contestada adoptando una perspectiva de larga duración y tomando en consideración el proceso de formación de la "parroquia clásica» de la Plena Edad Media ${ }^{81}$. La consolidación de una red parroquial con territorios bien definidos y sometida a la autoridad episcopal ha sido un proceso prolongado en el tiempo y que ha seguido patrones regionales diferenciados. Por lo que se refiere a los territorios considerados en este trabajo, Asturias y el País Vasco, se observan algunas diferencias importantes.

Uno de los principales mecanismos empleados en el País Vasco para crear la red parroquial ha sido la jerarquización de los centros de culto, promoviendo algunos y degradando otros. El proceso ha sido bien estudiado en las tres provincias vascas desde distintos ángulos y ha sido recientemente glosado por J. Á. García de Cortázar ${ }^{82}$. La principal consecuencia de esta jerarquización ha sido el abandono de un importante número de necrópolis e iglesias propias, la construcción de algunas iglesias parroquiales en localidades carentes de templos y la ampliación de las que alcanzaron este nuevo estatuto. Solamente en casos puntuales (como San Vincentejo, en Treviño), se mantuvo la dualidad de iglesia parroquial e iglesia propia de carácter señorial. En cambio, no está nada claro si estos procesos han tenido lugar también en Asturias y con estas mismas modalidades ${ }^{83}$. Pero resulta particularmente llamativo constatar que muchas iglesias «locales» altomedievales han sido halladas en excavaciones realizadas en templos parroquiales.

80 Que constituyen la expresión máxima de las identidades individuales en las sociedades locales altomedievales. Ver García Collado, Maite Iris. «El enterramiento privilegiado de San Román de Tobillas (Tobillas, Álava)». En Arqueología para el siglo XXI: Actas de las V Jornadas de Jóvenes en Investigación Arqueológica. Madrid: Jas Arqueología, 2013, pp. 131-136; Núñez MARCÉn, Julio. "Ermita de Andra Mari en Ullibarri Arana (Valle de Arana)». Arkeoikuska, 2000, vol. 99, pp. 264-265.

81 López Alsina, Fernando. «La reforma eclesiástica: la generalización de un modelo parroquial renovado». En La reforma gregoriana y su proyección en la cristiandad occidental: siglos XI-XII. Pamplona: Gobierno de Navarra, 2006, pp. 421-450.

82 García de Cortázar, La construcción de la Diócesis de Calahorra.

83 Calleja Puerta, Miguel. La formación de la red parroquial de la diócesis de Oviedo en la Edad Media. Oviedo: Real Instituto de Estudios Asturianos, 2000. 
Donde sí se advierte una diferencia radical es en los procesos constructivos mediante los cuales se transforman las iglesias altomedievales en templos parroquiales. Mientras que en el País Vasco -y en particular en Álava- es común que se mantenga y se reutilice al menos un muro perimetral de la primera iglesia, en Asturias o en Cataluña parece ser más común el arrasamiento y la refundación desde los cimientos de las iglesias «románicas». Dicho en otras palabras, las iglesias alavesas con fábricas altomedievales se presentan como verdaderas «matrioskas» que denotan, más allá de la dimensión puramente práctica, la voluntad de preservar la materialidad del templo antiguo. Incluso en ocasiones se reutilizan en las esquineras sepulcros probablemente procedentes de los cementerios previos.

Estas trayectorias podrían estar indicando que la identidad y cohesión de las comunidades locales sería más sólida en el País Vasco que en Asturias, en cuanto que la memoria social acumulada y transferida de la iglesia altomedieval a la parroquial se visibiliza en términos materiales. En cambio, el mayor protagonismo de la intervención señorial en la implantación de las parroquias en Asturias determina una discontinuidad en las arquitecturas en el marco de una persistencia del espacio sacro.

Gracias a los avances realizados por la arqueología en los últimos ańos se puede sostener que el número de iglesias realizadas en la Alta Edad Media fue muy superior al que hasta ahora se había aceptado. Como consecuencia de ello, el proceso de "parroquialización» no consistió necesariamente en la multiplicación de iglesias, cuanto en su transformación en lugares centrales a escala local a lo largo de un tiempo relativamente amplio. Dicho en otras palabras, el proceso de construcción de las territorialidades parroquiales no fue el resultado de la mera división de diócesis antiguas en segmentos, cuanto el resultado de la afirmación en la escala local de polos eclesiásticos. Todo ello comportó una compleja negociación, competición e interacción entre distintos agentes locales, por lo que la red parroquial no refleja necesariamente las jerarquías y espacialidades de las iglesias más antiguas o de los polos de poder previos ${ }^{84}$.

Seguir indagando, por lo tanto, las complejas conexiones existentes entre iglesias, polos de poder, asentamientos rurales y centros urbanos en términos de larga duración constituye una prioridad para comprender en toda su potencialidad las implicaciones de la implantación del sistema parroquial.

\section{Conclusiones}

La construcción de una iglesia privada es un acto de poder, grávido de consecuencias, puesto que son artefactos destinados a transformar o preservar el paisaje social. Esta es la razón principal por la que la mayor parte de los estudiosos han centrado su atención en las fundaciones realizadas por parte de las jerarquías laicas y eclesiásticas interpretadas como mecanismos de dominación. No obstante, a través de la arqueología es posible

84 Lauwers, Michel. «Paroisse, paroissiens et territoire. Remarques sur parochia dans les textes latins du Moyen Âge». Médiévales, 2005, vol. 49, pp. 11-31; Zadora-Rio, Des paroisses de Touraine aux communes d'Indre-et-Loire. 
sugerir que el número de iglesias privadas realizadas por las comunidades o por los líderes locales es mucho más numeroso del que se había considerado hasta la fecha. ¿Cómo interpretar desde una perspectiva territorial amplia este movimiento? Una primera lectura sería la de considerar estas iglesias "locales» como testimonio de la progresiva implantación del cristianismo y/o la imitación por parte de los subalternos de las iniciativas lideradas por los poderosos ${ }^{85}$.

Una segunda lectura, quizás más interesante, sería la de asumir que las comunidades locales eran fuentes activas de poder ${ }^{86}$. El campesinado en su conjunto, y algunos individuos en particular, contaban con una notable capacidad de agencia en un mundo basado en territorialidades e identidades relacionales. La fundación de iglesias empodera a los grupos subalternos para (re)configurar el orden social interno y relacionarse con el exterior. El capital simbólico y social que atesoran estas construcciones explica que un modesto edificio de madera pudiese ser aceptable en Guipúzcoa. Pero no lo era ni en Asturias ni en el Pirineo catalán, donde las fórmulas de representación y legitimación se arbitraban a través de otras tecnologías y formatos. Dicho en otras palabras, se puede sugerir que las comunidades locales desarrollaron lenguajes arquitectónicos y fórmulas de representación diferenciados respecto a la cultura de las élites. Sus iglesias no son una versión simplificada, "pobre» o «menor» de otras expresiones constructivas, sino instrumentos activos en la legitimación y construcción de un determinado orden local.

El preconcepto que sostiene que las iglesias de las comunidades han de ser de madera e «invisibles» en términos materiales recuerda mucho aquellas afirmaciones vigentes hasta hace pocos años que sostenían que los grupos subalternos serían ganaderos nómadas y, en consecuencia, su rastro material sería imposible de reconocer ${ }^{87}$. En este trabajo se ha pretendido argumentar que la naturaleza y las características de estas iglesias han de ser interpretadas en función de las formas con las que se construye, se legitima y se quiebra el tejido social de las comunidades.

Paradójicamente las iglesias gestadas en el seno de las comunidades locales constituyen una expresión de la agencia de los grupos subalternos, pero a medio o largo plazo han terminado revertiendo en nuevas formas de dominación por parte de los poderosos. Esta es una de las razones por la que no se realizaron templos en todas las localidades. La decisión de participar de una determinada ideología de legitimación y de construcción de un orden social tenía un precio elevado.

Comprender, en definitiva, los significados profundos de las tecnologías y los instrumentos de construcción del orden social requiere tomar una cierta distancia respecto a los valores contemporáneos y penetrar en los contextos en los que los artefactos son significativos.

85 Es el enfoque seguido, por ejemplo, en el estudio del territorio sudgálico contiguo al País Vasco, Colin, Marie-Geneviève. "Christianisation et peuplement des campagnes entre Garonne et Pyrénées, IVe- ${ }^{\mathrm{e}}$ siècles». Archéologie du Midi Médiéval, 2008, Suppl. 5, pp. 1-307.

${ }_{86}$ Desde una perspectiva de historia de la arquitectura ver Tosco, Carlo. Il castello, la casa, la chiesa: architettura e società nel medioevo. Torino: Einaudi, 2003.

87 Fossier, Robert. Paysans d'Occident: XI'-XIVe siècles. Paris: Presses Universitaires de France, 1984. 
Addison, David. «Property and 'publicness': bishops and lay-founded churches in post-Roman Hispania». Early Medieval Europe, 2020, vol. 282, pp. 175-196.

Álvarez Borge, Ignacio. «El proceso de transformación de las comunidades de aldea: una aproximación al estudio de la formación del feudalismo en Castilla (siglos x y xI)». Studia Historica. Historia Medieval, 1987, vol. 5, pp. 145-160.

Aratikos. Excavación arqueológica en la necrópolis de Santa Maria de Tejuela en Villanueva Soportilla (Bozóo, Burgos). Burgos: Memoria técnica inédita, 2010.

Arias Páramo, Lorenzo. Enciclopedia del prerrománico en Asturias. Aguilar de Campoo: Fundación Santa María la Real, 2007.

Azkarate Garai-Olaun, Agustín y García Camino, Iñaki. Estelas e inscripciones medievales en el País Vasco occidental (ss. VI-XI). Bilbao: Universidad del País Vasco, 1996.

Azkarate Garai-Olaun, Agustín y Sánchez Zufiaurre, Leandro. "Las iglesias prefeudales en Álava: cronotipología y articulación espacial». Arqueología de la Arquitectura, 2003, vol. 2, pp. 25-36.

Azkarate Garai-Olaun, Agustín y Solaun Bustinza, José Luis. "Tipologías domésticas y técnicas constructivas en la primitiva Gasteiz (País Vasco) durante los siglos viII al XII d. C». Arqueología de la Arquitectura, 2013, vol. 9, pp. 103-128.

BARAut, Cebrià. «Les actes de consagracions d'esglésies del bisbat d'Urgell (segles IX-XII)». Urgellia, 1978, vol. 1, pp. 11-182.

Barrow, Julia. The clergy in the medieval world: secular clerics, their families and careers in northwestern Europe, c. 800-c. 1200. Cambridge: Cambridge University Press, 2015.

BlaIr, John. The Church in Anglo-Saxon society. Oxford: Oxford University Press, 2005.

Bonnassie, Pierre. "Conclusion». En Villages pyrénéens: morphogenèse d'un habitat de montagne. Toulouse: CNRS, 2001, pp. 283-297.

Bonnassie, Pierre. Del esclavismo al feudalismo en Europa occidental. Barcelona: Crítica, 1992.

Brogiolo, Gian Pietro. «San Tomé di Carvico. Archeologia di una chiesa altomedievale». En Carvico alle pendici del Monte Canto. Milano: Comune di Carvico, 2016, pp. 161-223.

Brookes, Stuart y Reynolds, Andrew. «Territoriality and Social Stratification: The Relationship between Neighbourhood and Polity in Anglo-Saxon England». En Polity and Neighbourhood in Early Medieval Europe. Turnhout: Brepols, 2019, pp. 267-304.

Caballero Zoreda, luis; Mateos Cruz, Pedro y García de Castro Valdés, César. Asturias entre visigodos y mozárabes. Madrid: Consejo Superior de Investigaciones Científicas, 2012.

Caballero Zoreda, Luis y Utrero Agudo, María Angeles. «El ciclo constructivo de la Alta Edad Media hispánica. Siglos viII-X». Archeologia dell’architettura, 2013, vol. 18, pp. 127146.

Calleja Puerta, Miguel. La formación de la red parroquial de la diócesis de Oviedo en la Edad Media. Oviedo: Real Instituto de Estudios Asturianos, 2000.

Canuto, Marcello-Andrea y Yaeger, Jason. Archaeology of communities: a new world perspective. London: Routledge, 2000.

Carvajal Castro, Álvaro. Bajo la máscara del «Regnum»: La monarquía asturleonesa en León (8541037). Madrid: Consejo Superior de Investigaciones Científicas, 2017.

Carvajal Castro, Álvaro y Narbarte Hernández, Josu. «Royal power and proprietary churches in the eleventh-century Kingdom of Pamplona». Journal of Medieval Iberian Studies, 2019, vol. 11, pp. 115-134. 
Castillo, Alberto del. Excavaciones altomedievales en las provincias de Soria, Logroño y Burgos. Madrid: Ministerio de Educación y Ciencia, 1972.

Castresana López, Álvaro. Corpus Inscriptionum Christianarum et Mediaevalium Provinciae Burgensis: (ss. IV-XIII). Oxford: Archaeopress, 2015.

Chavarría, Alexandra. Archeologia delle chiese: dalle origini all'anno Mille. Roma: Carocci, 2009.

ColIn, Marie-Geneviève. "Christianisation et peuplement des campagnes entre Garonne et Pyrénées, Iv $\mathrm{V}^{\mathrm{e}} \mathrm{\textrm {X }}$ siècles». Archéologie du Midi Médiéval, 2008, Suppl. 5, pp. 1-307.

Davies, Wendy. Acts of giving: individual, community, and church in tenth-century Christian Spain. Oxford: Oxford University Press, 2007.

Davies, Wendy. Christian Spain and Portugal in the early Middle Ages: texts and societies. Abingdon: Routledge, 2020.

Davies, Wendy. Small Worlds: The Village Community in Early Medieval Brittany. Berkeley: University of California Press, 1988.

Diego Santos, Francisco. Inscripciones medievales de Asturias. Oviedo: Gobierno del Principado de Asturias, 1995.

Escalona Monge, Julio. "In the name of a distant king: representing royal authority in the county of Castile, c. 900-1038». Early Medieval Europe, 2016, vol. 24, pp. 74-102.

Escalona Monge, Julio. Sociedad y territorio en la Alta Edad Media castellana: la formación del Alfoz de Lara. Oxford, 2002.

Escalona, Julio y Martín Viso, Iñaki. "The Life and Death of an Historiographical Folly: The Early Medieval Depopulation and Repopulation of the Duero Basin». En Beyond the Reconquista: New Directions in the History of Medieval Iberia (711-1085). Leiden: Brill, 2020, pp. 21-51.

Etxezarraga Ortuondo, Iosu. «San Pedro de Iromendi: VI Campaña». Arkeoikuska: Investigación Arqueológica, 2017, pp. 358-363.

Etxezarraga Ortuondo, Iosu. El laicado y sus instituciones en la configuración religiosa de Gipuzkoa en la Edad Media. Tesis Doctoral. Universidad del País Vasco, 2017.

Faravel, Sylvie. "Bilan des recherches sur les origines de la paroisse en Aquitaine ( $\mathrm{IV}^{\mathrm{e}}-\mathrm{X}^{\mathrm{e}}$ siècle)». En Aux origines de la paroisse rurale en Gaule méridionale ( $V^{\ell}-I X^{e}$ siècles). Paris: Errance, 2005, pp. 150-158.

Fossier, Robert. Paysans d'Occident: $X I^{e}-X I V^{e}$ siècles. Paris: Presses Universitaires de France, 1984.

García Álvarez-Busto, Alejandro. «Iglesias, cementerios, poblamiento y ordenación social y territorial en el Reino de Asturias». Anejos de Nailos: Estudios Interdisciplinares de Arqueología, 2019, vol. 5, pp. 483-512.

García Álvarez-Busto, Alejandro y MuñIz López, Iván. Arqueología medieval en Asturias. Gijón: Trea, 2010.

García Camino, Ińaki. «Zarautz antes que Zarautz’. La primitiva aldea en el contexto de la historia altomedieval de los territorios del litoral vasco». Munibe. Suplemento, 2009, vol. 27, pp. 376-399.

García Camino, Ińaki. Arqueología y poblamiento en Bizkaia, siglos VI-XII: la configuración de la sociedad feudal. Bilbao: Diputación Foral de Bizkaia, 2002.

García Camino, Iñaki; González Cembellín, Juan Manuel y Santana Ezquerra, Alberto. «La arquitectura prerrománica vizcaína». Kobie. Bellas Artes, 1987, vol. 4, pp. 7-38.

García Collado, Maite Iris. «El enterramiento privilegiado de San Román de Tobillas (Tobillas, Álava)». En Arqueología para el siglo XXI: Actas de las V Jornadas de Jóvenes en Investigación Arqueológica. Madrid: Jas Arqueología, 2013, pp. 131-136. 
García de Castro Valdés, César. Arqueología cristiana de la Alta Edad Media en Asturias. Oviedo: RIDEA, 1995.

García de Cortázar, José Ángel. La construcción de la diócesis de Calahorra en los siglos X a XIII: la iglesia en la organización social del espacio. Logroño: Instituto de Estudios Riojanos, 2018.

García De Cortázar, José Ángel. Sociedad y organización del espacio en la España medieval. Granada: Universidad de Granada, 2004.

García de Cortázar, José Ángel; Arízaga Bolumburu, Beatriz; Martínez Ochoa, Rosa M. et al. Introducción a la Historia Medieval de Álava, Guipuizcoa y Vizcaya en sus textos. San Sebastián: Txertoa, 1979.

García García, María Elida. «Pequeños propietarios en Asturias: (siglos x y xI)». Asturiensia Medievalia, 1986, vol. 5, pp. 33-53.

García Gómez, Ismael. Vitoria-Gasteiz y su hinterland. Evolución de un sistema urbano entre los siglos XI y XV. Bilbao: Universidad del País Vasco, 2017.

Gutiérrez GonzÁLez, José Avelino. «Arqueología de la temprana Edad Media en Asturias: sobre los orígenes antiguos de Oviedo». En Arqueología de época histórica en Asturias. Oviedo: RIDEA, 2018, pp. 13-46.

Hamilton, Sarah. Church and people in the medieval west, 900-1200. Abingdon, Oxon: Routledge, 2013.

Hernando, Almudena. La fantasía de la individualidad: sobre la construcción sociohistórica del sujeto moderno. Madrid: Katz Editores, 2012.

HODDER, Ian. Interpretación en arqueología: corrientes actuales. Barcelona: Crítica, 1988.

Horden, Peregrine y Purcell, Nicholas. The corrupting sea: a study of Mediterranean history. Oxford: Wiley-Blackwell, 2000.

IbáŃez EcheVerría, Álex. Santa María la Real de Zarautz (País Vasco): continuidad y discontinuidad en la ocupación de la costa vasca entre los siglos V a. C. y XIV d. C. San Sebastián: Sociedad de Ciencias Aranzadi, 2009.

Ingold, Tim. Antropología: ¿por qué importa? Madrid: Alianza, 2020.

LARREA Conde, Juan José. "Construir iglesias, construir territorio: las dos fases altomedievales de San Román de Tobillas (Álava)». En Monasteria et territoria. Elites, edilicia y territorio en el Mediterráneo medieval (siglos V-XI). Oxford: Archaeopress, 2007, pp. 321-336.

Lauwers, Michel. «Paroisse, paroissiens et territoire. Remarques sur parochia dans les textes latins du Moyen Âge». Médiévales, 2005, vol. 49, pp. 11-31.

Lemonnier, Pierre. Elements for an anthropology of technology. Ann Arbor: Museum of Anthropology, University of Michigan, 1992.

López Alsina, Fernando. "La reforma eclesiástica: la generalización de un modelo parroquial renovado». En La reforma gregoriana y su proyección en la cristiandad occidental: siglos XI-XII. Pamplona: Gobierno de Navarra, 2006, pp. 421-450.

Martínez Sopena, Pascual. La tierra de Campos occidental: poblamiento, poder y comunidad del siglo X al XIII. Valladolid: Institución Cultural Simancas, 1985.

Martín Viso, Ińaki. «Las propiedades regias y la formación del Reino Asturleonés (850-950)». En Biens publics, biens du roi. Les bases économiques des pouvoirs royaux dans le haut Moyen Âge. Turnhout: Brepols, 2019, pp. 179-212.

Martín Viso, Iñaki. Poblamiento y estructuras sociales en el norte de la Peninsula Ibérica (siglos VIXIII). Salamanca: Universidad de Salamanca, 2000.

Mériaux, Charles. "La compétition autour des églises locales dans le monde franc». En Compétition et sacré au haut Moyen Âge: entre médiation et exclusion. Turnhout: Brepols, 2015, pp. 85-102. 
MSARqueo. Memoria técnica de la excavación arqueológica de la necrópolis de San Andrés de Veigas. Oviedo: Memoria inédita, 2012.

Narbarte Hernández, Josu; Iriarte, Eneko; Rad, Carlos, et al. «On the origin of rural landscapes: Looking for physico-chemical fingerprints of historical agricultural practice in the Atlantic Basque Country (N Spain)». Science of the Total Environment, 2019, vol. 681, pp. 66-81.

NúÑez Marcén, Julio. «Ermita de Andra Mari en Ullibarri Arana (Valle de Arana)». Arkeoikuska, 2000, vol. 99, pp. 264-265.

Ordeig i Mata, Ramon. Les Dotalies de les esglésies de Catalunya, segles IX-XII. Brcelona: Universitat de Barcelona, 1990.

Parker Pearson, Michael. The archaeology of death and burial. Stroud: Sutton, 2003.

Pastor de Togneri, Reyna y Rodríguez López, Ana. «Reciprocidades, intercambio y jerarquía en las comunidades medievales». Hispania: Revista Española de Historia, 2000, vol. 204, pp. 63-101.

PÉREZ, Mariel. «Iglesias propias, élites rurales y poder eclesiástico en León (siglos XI-XIII)». En Comunidades en conflicto. Elites comunitarias y poder politico en la Peninsula Ibérica (siglos IX a XVI). Buenos Aires: Universidad de Buenos Aires, 2018, pp. 41-67.

Quirós Castillo, Juan Antonio. "An archaeology of 'small worlds': social inequality in early medieval Iberian rural communities». Journal of Medieval Iberian Studies, 2020, vol. 12, n. ${ }^{\circ}$ 1, pp. 3-27.

Quirós Castillo, Juan Antonio. «Arqueología de los condados castellanos. Sociedades locales y prácticas políticas en Lantarón (siglos IX-X)». SPAL: Revista de Prehistoria y Arqueología de la Universidad de Sevilla, 2020, en prensa.

Quirós Castillo, Juan Antonio. «Longhouses, biografía de la casa y complejidad social en el noroeste peninsular en la Alta Edad Media». Arqueología de la Arquitectura, 2017, vol. 14.

Quirós Castillo, Juan Antonio. Arqueología del campesinado medieval: la Aldea de Zaballa. Bilbao: Universidad del País Vasco, 2012.

Quirós Castillo, Juan Antonio y Fernández Mier, Margarita. «Para una historia social de la arquitectura monumental altomedieval asturiana». En Asturias entre visigodos y mozárabes. Madrid: Consejo Superior de Investigaciones Científicas, 2012, pp. 27-53.

Quirós Castillo, Juan Antonio y Santos Salazar, Igor. «I villaggi medievali nell'Alto Ebro alla luce delle fonti scritte e dell'archeologia. L'emergere dei leader dei villaggi e l'articolazione dei poteri territoriali nel x secolo». En Paesaggi, comunità, villaggi medievali. Spoleto: Centro di Studi sull'Altomedioevo, 2012, pp. 257-282.

Rapoport, Amos. Vivienda y cultura. Barcelona: Gustavo Gili, 1972.

Requejo Pagés, Otilia. "II fase de restauración en la iglesia de San Vicente de Serrapio, Aller (1991-1992): resultados arqueológicos». En Excavaciones arqueológicas en Asturias: 1991-94. Oviedo: Principado de Asturias, 1995, pp. 293-296.

Requejo Pagés, Otilia; Arca Miguélez, María Cristina; Arias Páramo, Lorenzo et al. «Descubrimiento de la antigua iglesia de San Juan de Riomiera (Collanzo, Aller)». En Excavaciones arqueológicas en Asturias: 1999-2002. Oviedo: Principado de Asturias, 2007, pp. 347-356.

Riu i Barrera, Eduard. Memòria de l'excavació del temple de Sant Andreu de Sagàs. Barcelona: Generalitat de Catalunya, 1986.

SACK, Robert David. Human territoriality: its theory and history. Cambridge: Cambridge University Press, 1986. 
PERTENECER Y DIFERENCIARSE. IGLESIAS «LOCALES»

Y AGENCIA CAMPESINA EN EL NOROESTE DE LA PENÍNSULA IBÉRICA

JUAN ANTONIO QUIRÓS CASTILLO

Sánchez Pardo, José Carlos; Torre Llorca, María Jesús de la y Fernández Ferreiro, Marcos. "Élites, arquitectura y fundación de iglesias en Galicia entre los siglos Ix y x». Reti Medievali, 2018, vol. 19, n. ${ }^{\circ}$ 2, pp. 311-366.

SÁnchez Zufiaurre, Leandro. Técnicas constructivas medievales: Nuevos documentos arqueológicos para el estudio de la Alta Edad Media en Álava. Vitoria-Gasteiz: Gobierno Vasco, 2007.

Sanz Fuentes, María Josefa y Calleja Puerta, Miguel. Litteris confirmentur: lo escrito en Asturias en la Edad Media. Oviedo: Cajastur, 2005.

Sarasola, Nerea y Moraza, Alfredo. Arkeologia 0.5 - Arqueologia Medieval en Gipuzkoa. San Sebastián: Diputación Foral de Gipuzkoa, 2012.

Sevilla Guzmán, Eduardo y Pérez Yruela, Manuel. «Para una definición sociológica del campesinado". Agricultura y Sociedad, 1976, vol. 1, pp. 15-39.

Tomás Faci, Guillermo. Montañas, comunidades y cambio social en el Pirineo medieval: Ribagorza en los siglos X-XIV. Zaragoza: Prensas Universitarias de Zaragoza, 2016.

Tosco, Carlo. Il castello, la casa, la chiesa: architettura e società nel medioevo. Torino: Einaudi, 2003.

Utrero Agudo, María Ángeles. Iglesias altomedievales en Asturias: Arqueología y Arquitectura. Madrid: Consejo Supeerior de Investigaciones Científicas, 2016.

Vésteinsson, Orri; Sveinbjörnsdóttir, Árný; Gestsdóttir, Hildur et al. «Dating religious change: Pagan and Christian in Viking Age Iceland». Journal of Social Archaeology, 2019, vol. 19, n. ${ }^{\circ}$ 2, pp. 162-180.

Wicкham, Chris. «Conclusiones». En Vasconia en la Alta Edad Media, 450-1000: poderes y comunidades rurales en el norte penínsular. Bilbao: Universidad del País Vasco, 2011, pp. 87-90.

Wood, Susan. The proprietary church in the medieval West. Oxford: Oxford University Press, 2006.

Wolf, Eric R. Los campesinos. Barcelona: Labor, 1971.

Zadora-Rio, Elisabeth. Des paroisses de Touraine aux communes d'Indre-et-Loire: La formation des territoires. Tours: Ferac Editions, 2008. 